\title{
Preferential Flow Paths and Heat Pipes: Results from Laboratory Experiments on Heat-Driven Flow in Natural and Artificial Rock Fractures
}

Timothy J. Kneafsey

Karsten Pruess

Earth Sciences Division

Lawrence Berkeley National Laboratory

Level 4 Milestone ID: SPL6A5M4

WSB 1.2.3.12.2 (SA\#TR3C2FB2)

Due Date: 23 June 1997

\section{Abstract}

Water flow in fractures under the conditions of partial saturation and thermal drive may lead to fast flow along preferential localized pathways and heat pipe conditions. Water flowing in fast pathways may ultimately. contact waste packages at Yucca Mountain and transport radionuclides to the accessible environment. Sixteen experiments were conducted to visualize liquid flow in glass fracture models, a transparent epoxy fracture replica, and a rock/replica fracture assembly. Spatially resolved thermal monitoring was performed in seven of these experiments to evaluate heat-pipe formation. Depending on the fracture apertures and flow conditions, various flow regimes were observed including continuous rivulet flow for high flow rates, intermittent rivulet flow and drop flow for intermediate flow rates, and film flow for low flow rates and wide apertures. These flow regimes were present in both fracture models and in the replica of a natural fracture. Heat-pipe conditions indicated by low thermal gradients were observed in five experiments. Conditions conducive to heat-pipe formation include an evaporation zone, condensation zone, adequate space for vapor and liquid to travel, and appropriate fluid driving forces. In one of the two experiments where heat pipe conditions were not observed, adequate space for liquid-vapor counterflow was not provided. Heat pipe conditions were not established in the other, because liquid flow was inadequate to compensate for imbibition and the quantity of heat contained within the rock. 


\section{Introduction}

Heat released from high-level nuclear waste packages in a partially saturated environment can have major impacts on moisture distribution and migration. The tuff formations in the unsaturated zone at Yucca Mountain contain from 40 to $80 \%$ or more liquid water in the pore space, which will be vaporized as formation temperatures approach and exceed the boiling point at prevailing pressures. This will cause pressurization of the gas phase, which will drive vapor away from the heat source. In a fractured medium, the vapor is expected to flow primarily in the fractures. Condensation will take place as the vapor invades cooler rock, which will generate mobile water in the fractures. The water will flow under the combined action of gravity and capillary forces. It may, in part, return to the vicinity of the waste packages where it would again be subject to vaporization (Buscheck and Nitao, 1993). Mathematical modeling studies have indicated that vaporization may not be complete. Water flowing down (sub-) vertical fractures may partially escape vaporization, and may migrate considerable distances through fractured rock that is at above-boiling temperatures (Pruess, 1997). This raises the obvious concern that flowing condensate may contact waste packages, and provide a pathway for the transport of water-soluble radionuclides.

The amount of water that could be generated by vaporization-condensation cycles is potentially very large. From the data given by Pruess and Tsang (1994) one can deduce that a single multi-purpose canister can generate condensate at an average rate of several cubic meters per year over a 10,000-year period. For a nominal thermal loading of $57 \mathrm{~kW} / \mathrm{acre}$, this translates into an average equivalent percolation flux from condensate of $23.1 \mathrm{~mm} / \mathrm{yr}$ over 1,000 years, and $5.2 \mathrm{~mm} / \mathrm{yr}$ over 10,000 years. These numbers are comparable to or larger than current estimates of net infiltration at Yucca Mountain (A. Flint et al., 1996). The condensate would be generated in the immediate vicinity (meters) of the waste packages, so that its impact on waste package and repository performance is likely to be larger than the impact of a similar amount of water introduced at the land surface.

These considerations suggest that thermally driven flow processes induced by repository heat may well be as important or even more important for repository performance than natural infiltration (Buscheck and Nitao, 1993; Pruess and Tsang, 1994). A combined program of field, laboratory, and theoretical studies is needed to gain an understanding of these processes, so that they may be properly taken into account for waste package and repository design, and for repository performance evaluation. Key issues include the potential development of fast preferential water flow paths, migration of transient water pulses through heated regions, and the development of heat pipe conditions. There is a long track record of mathematical modeling studies devoted to thermally driven processes in the Yucca Mountain project, see for example the references given in the review article by Pruess and Tsang (1994). In situ heater tests are underway at the ESF facility (CRWMS M\&O, 1997). 
The present report summarizes first results from a laboratory experimental program, started in December, 1996, on vaporizing water flow in hot fractures. We present and discuss results of a limited number of laboratory experiments to visualize and study thermally driven liquid flow phenomena, including preferential liquid flow paths in fractures and the development of heat pipes. These mechanisms could give rise to fast transport of radionuclides. Two types of experiments have been performed. The first type investigates the thermally driven movement of liquid in a fractured, partially saturated medium at elevated temperatures. The second type of experiment examines the likelihood that heat pipe conditions can develop in fractures.

\section{Setup for Flow Visualization Experiments}

Sixteen experiments were performed in fracture models and fracture replicas. Fracture models were composed of various assemblies of sandblasted obscure (non-flat) and flat glass plates. Transparent epoxy fracture replicas were cast from molds taken from natural fracture faces. In the experiments, regions of fracture models and replicas were subjected to temperatures exceeding the boiling point of the liquid.

Fracture models were prepared using ordinary $1 / 4$ inch thick flat plate glass and 3/16-inchthick P516 obscure glass. The obscure glass has a random pattern of rounded projections and depressions, with an estimated amplitude on the order of 100 microns, and a projectionto-projection spacing of about $2 \mathrm{~mm}$. Sandblasting was used to roughen many of the glass plates resulting in small pits covering the entire surface. Two sizes of aluminum oxide grit (80 and 240) were used on different pieces of glass to impart different roughnesses. The 80 grit left pits estimated to be on the order of 10 microns deep. The 240 grit left smaller pits resulting in a smoother surface. Large sheets of flat glass may vary from being truly flat by up to 150 microns; however, the glass plates used in these experiments appeared flat. Fracture models were assembled by clamping together clean plates of glass sized $21.6 \times 33$ $\mathrm{cm}$ with or without shims, and applying epoxy to the bottom, side, and top edges, leaving three approximately evenly spaced $1.5 \mathrm{~cm}$ openings on the top (Figure 1). Transparent fracture replicas are epoxy casts (Eccobond 27, W.R. Grace Co., Canton, MA) made from a silicone mold (Silpak R2230, Silpak Inc., Pomona CA) of the fracture surfaces. Both the silicone mold and the epoxy cast are cured at room temperature. Details of the replicamaking procedure, originally developed by Gentier (1986), are described in Su (1995) and Persoff and Pruess (1995).

Pentane was used instead of water as the working fluid because the lower boiling point ( 36.1 ${ }^{\circ} \mathrm{C}$ at one atmosphere pressure) simplifies the experimental setup. This also allows for a more accurate portrayal of expected boundary conditions because the pentane boiling point is closer to the ambient laboratory temperature thus producing lower temperature gradients 
more akin to what would be expected in heating geologic media. The combined use of pentane and fracture models and replicas allows for direct visualization of liquid behavior in the void space and a visual investigation of preferential flow path development without the addition of dyes. Some properties of pentane and water relevant to flow and boiling which will be important in scaling efforts to be conducted in FY 98 are presented in Figure 2 (surface tensions and vapor pressures, Lide and Rossini et al.; enthalpy of vaporization, Wark, Rossini et al., and Vargaftik; kinematic viscosity, calculated from Lide and Rossini et al.; steam kinematic viscosity calculated from Welty et al. and Meyer, et al.; pentane vapor kinematic viscosity calculated from Vargaftik). The surface tension of water is greater than that of pentane, thus capillary forces will be stronger in similar systems containing water. Water has a much higher enthalpy of vaporization, thus water fingers and films would likely penetrate much further into a boiling region than pentane under similar conditions. The kinematic viscosities of liquid water and liquid pentane are similar near boiling temperatures, as are vapor pressures. The kinematic viscosity of steam is an order of magnitude higher than that of pentane vapor, which will result in water vapor being more difficult to force through fractures than pentane under similar conditions.

A summary of the experiments performed is presented in Table 1 . In Table 1, the experiment number is followed by the designations that describe the two fracture model or replica faces. The designations include SOG for sandblasted obscure glass, SFG for sandblasted flat glass, and FG for flat glass. Thus, SOG/FG designates a fracture model with one face sandblasted obscure glass, and the other face flat glass. Some fracture models were used in several experiments.

Table 1. Summary of experiments and major observations.

\begin{tabular}{|l|l|l|}
\hline Experiment & $\begin{array}{l}\text { Conditions/Estimated } \\
\text { Aperture }\end{array}$ & Major Observations \\
\hline $\mathbf{1 ~ S O G / F G *}$ & $\begin{array}{l}\text { Aperture varies from near zero to an } \\
\text { estimated few hundred microns with } \\
\text { random pattern of narrow/wide } \\
\text { apertures spaced about 1 mm apart. } \\
\text { Sandblasted with 80 grit aluminum } \\
\text { oxide for coarse surface roughness. } \\
\begin{array}{l}\text { Partially submerged fracture model. } \\
\text { Temperature increasing, then } \\
\text { decreasing, then increasing. }\end{array}\end{array}$ & $\begin{array}{l}\text { Film flow penetrating warmed region. } \\
\text { Finger flow penetrating warmed region. } \\
\text { increasing bath temperature. } \\
\text { Rapid evaporation events (REEs**) } \\
\text { observed. }\end{array}$ \\
\hline 2 SOG/FG & $\begin{array}{l}\text { Partially submerged fracture model. } \\
\text { Temperature increasing. Pentane } \\
\text { entirely contained within warmed } \\
\text { region at startup. Sandblasted with } \\
\text { 80 grit aluminum oxide for coarse } \\
\text { surface roughness. }\end{array}$ & $\begin{array}{l}\text { Film flow penetrating warmed region. } \\
\text { Finger flow penetrating warmed region. } \\
\text { Film and finger lengths decreased with } \\
\text { increasing bath temperature. } \\
\text { Large REE during dryout. }\end{array}$ \\
\hline
\end{tabular}




\begin{tabular}{|c|c|c|}
\hline 3 SFG/FG & $\begin{array}{l}\text { Aperture varies from near zero to an } \\
\text { estimated hundred microns with } \\
\text { pattern of narrow/wide apertures due } \\
\text { to sandblasting spaced about } 2 \mathrm{~cm} \\
\text { apart. Sandblasted with } 80 \text { grit } \\
\text { aluminum oxide for coarse surface } \\
\text { roughness. Partially submerged } \\
\text { fracture model. Temperature } \\
\text { increasing, then decreasing. }\end{array}$ & $\begin{array}{l}\text { Film flow penetrating warmed region. } \\
\text { Finger flow penetrating warmed region. } \\
\text { Film and finger lengths decreased with } \\
\text { increasing bath temperature. }\end{array}$ \\
\hline 4 SOG/SOG & $\begin{array}{l}\text { More variable than the SOG/FG } \\
\text { model with an aperture varying } \\
\text { from near zero to an estimated } \\
\text { several hundred microns with } \\
\text { random pattern of narrow/wide } \\
\text { apertures spaced about } 1 \mathrm{~mm} \text { apart. } \\
\text { Sandblasted with } 80 \text { grit aluminum } \\
\text { oxide for coarse surface roughness. } \\
\text { Partially submerged fracture model. } \\
\text { Temperature increasing, then } \\
\text { decreasing. }\end{array}$ & $\begin{array}{l}\text { Film flow penetrating warmed region. } \\
\text { Finger flow penetrating warmed region. } \\
\text { Film and finger lengths decreased with } \\
\text { increasing bath temperature. } \\
\text { REEs observed. }\end{array}$ \\
\hline 5 SOG/SOG & $\begin{array}{l}\text { Partially submerged fracture model. } \\
\text { Temperature increasing, then } \\
\text { decreasing. Two infiltration events. } \\
\text { Sandblasted with } 80 \text { grit aluminum } \\
\text { oxide for coarse surface roughness. }\end{array}$ & $\begin{array}{l}\text { Film flow penetrating warmed region. } \\
\text { Finger flow penetrating warmed region. } \\
\text { Film and finger lengths decreased with } \\
\text { increasing bath temperature. } \\
\text { REEs observed. }\end{array}$ \\
\hline 6 SFG/SFG & $\begin{array}{l}\text { More variable than the SFG/FG } \\
\text { model with aperture varying from } \\
\text { near zero to an estimated few } \\
\text { hundred microns with a vertical } \\
\text { pattern of narrow/wide apertures } \\
\text { spaced about } 2 \mathrm{~cm} \text { apart. } \\
\text { Sandblasted with } 80 \text { grit aluminum } \\
\text { oxide for coarse surface roughness. } \\
\text { Partially submerged fracture model. } \\
\text { Temperature increasing, then } \\
\text { decreasing. }\end{array}$ & $\begin{array}{l}\text { Finger flow penetrating warmed region. } \\
\text { Finger lengths decreased with increasing } \\
\text { bath temperature. } \\
\text { Frequent, violent REEs observed affecting } \\
\text { location of saturated islands and film } \\
\text { thicknesses in the condensation halo. }\end{array}$ \\
\hline $\begin{array}{l}7 \text { SOG/SOG } \\
\text { Circular } \\
\text { Heated } \\
\text { Regions }\end{array}$ & $\begin{array}{l}\text { Circular warmed disks attached to } \\
\text { model. Sandblasted with } 80 \text { grit } \\
\text { aluminum oxide for coarse surface } \\
\text { roughness. }\end{array}$ & $\begin{array}{l}\text { Stable, dry region in warmed region beneath } \\
\text { the warmed disks except when large pentane } \\
\text { seepage occurred, causing fingers to flow } \\
\text { into warmed region. }\end{array}$ \\
\hline $\begin{array}{l}8 \text { SOG/FG } \\
\text { Finger } \\
\text { Location } \\
\text { Repeatability }\end{array}$ & $\begin{array}{l}\text { Fracture sequentially submerged to } \\
\text { different depths in a constant } \\
\text { temperature bath warmer than the } \\
\text { boiling point, and sequentially } \\
\text { raised to the same depths. } \\
\text { Sandblasted with } 80 \text { grit aluminum } \\
\text { oxide for coarse surface roughness. }\end{array}$ & $\begin{array}{l}\text { Major fingers formed in approximately the } \\
\text { same location when submersion depth was } \\
\text { the same; however, the same number of } \\
\text { fingers did not always form. }\end{array}$ \\
\hline $\begin{array}{l}9 \text { SFG/SFG } \\
\text { Wall } \\
\text { Thickness/ } \\
\text { Heat Pipe } \\
\text { Development }\end{array}$ & $\begin{array}{l}\text { Partially submerged fracture model. } \\
\text { Temperature increasing, then } \\
\text { decreasing. Two glass thicknesses. } \\
\text { Sandblasted with } 80 \text { grit aluminum } \\
\text { oxide for coarse surface roughness. } \\
\text { Infrared temperature monitoring of } \\
\text { region above warmed region } \\
\text { performed. }\end{array}$ & $\begin{array}{l}\text { Frequent, violent REEs with thinner glass. } \\
\text { Fewer, less violent REEs with thicker glass. } \\
\text { Longer, wider fingers with thicker glass. } \\
\text { Finger lengths decreased with increasing } \\
\text { bath temperature. } \\
\text { Heat pipe regions of similar size and shape } \\
\text { for thin and thick glass. }\end{array}$ \\
\hline
\end{tabular}




\begin{tabular}{|c|c|c|}
\hline $\begin{array}{l}10 \text { SFG/SFG } \\
\text { Non-uniform } \\
\text { Heating }\end{array}$ & $\begin{array}{l}\text { Partially submerged fracture model. } \\
\text { Temperature increasing, then } \\
\text { decreasing. } 1.9 \times 2.5 \mathrm{~cm} \text { Lexan } \\
\text { strips placed across model to alter } \\
\text { heat flow. Sandblasted with } 80 \text { grit } \\
\text { aluminum oxide for coarse surface } \\
\text { roughness. }\end{array}$ & $\begin{array}{l}\text { On warming, Lexan strips hindered heat } \\
\text { flow into model in warmed region and } \\
\text { impeded heat flow out of model in non- } \\
\text { warmed region. On cooling the Lexan } \\
\text { hindered heat flow out of the model in both } \\
\text { regions. These heat flow heterogeneities } \\
\text { altered condensation halo location, finger } \\
\text { location and length. } \\
\text { Finger lengths decreased with increasing } \\
\text { bath temperature. }\end{array}$ \\
\hline $\begin{array}{l}11 \text { SOG/SOG } \\
\text { Impermeable } \\
\text { Barriers }\end{array}$ & $\begin{array}{l}\text { More variable than the SOG/FG } \\
\text { model, with an aperture varying } \\
\text { from near zero to several hundred } \\
\text { microns, with random pattern of } \\
\text { narrow/wide apertures spaced about } \\
1 \mathrm{~mm} \text { apart. Partially submerged } \\
\text { fracture model. Temperature } \\
\text { increasing, then decreasing. } \\
\text { Impermeable epoxy barriers placed } \\
\text { to form a funnel and focus flow. } \\
\text { Sandblasted with } 80 \text { grit aluminum } \\
\text { oxide for coarse surface roughness. } \\
\text { Infrared temperature monitoring of } \\
\text { region above warmed region } \\
\text { performed. }\end{array}$ & $\begin{array}{l}\text { Condensation halo and fingers initially } \\
\text { formed below barrier. Later, pentane } \\
\text { pooled in the funnel center, and pentane } \\
\text { vapors traveled upward on the outside of the } \\
\text { funnel. Longer fingers were present from } \\
\text { the funnel center than other locations. } \\
\text { Number of fingers under notch was not } \\
\text { constant. Higher gas pressure present below } \\
\text { the barriers. } \\
\text { Finger lengths decreased with increasing } \\
\text { bath temperature. } \\
\text { Regions of low temperature gradient } \\
\text { indicating vapor-liquid counterflow (heat- } \\
\text { pipe behavior) were present outside of the } \\
\text { barrier region. }\end{array}$ \\
\hline $\begin{array}{l}12 \text { SFG/SFG } \\
\text { Wide } \\
\text { Aperture }\end{array}$ & $\begin{array}{l}\text { Nominal aperture of } 0.76 \mathrm{~mm} \text { with a } \\
\text { vertical pattern of variable surface } \\
\text { roughness spaced about } 2 \mathrm{~cm} \text { apart. } \\
\text { Sandblasted with } 80 \text { grit aluminum } \\
\text { oxide for coarse surface roughness. } \\
\text { Partially submerged fracture model. } \\
\text { Temperature increasing, then } \\
\text { decreasing. } \\
\text { Infrared temperature monitoring of } \\
\text { region above warmed region } \\
\text { performed. }\end{array}$ & $\begin{array}{l}\text { Region of low temperature gradient } \\
\text { indicating vapor-liquid counterflow (heat- } \\
\text { pipe behavior) was present throughout the } \\
\text { condensation halo region. }\end{array}$ \\
\hline $\begin{array}{l}13 \text { SOG/SOG } \\
\text { Fine Surface } \\
\text { Roughness }\end{array}$ & $\begin{array}{l}\text { More variable than the SOG/FG } \\
\text { model with an aperture varying } \\
\text { from near zero to an estimated } \\
\text { several hundred microns with } \\
\text { random pattern of narrow/wide } \\
\text { apertures spaced about } 1 \mathrm{~mm} \text { apart. } \\
\text { Sandblasted with } 240 \text { grit aluminum } \\
\text { oxide for fine surface roughness. } \\
\text { Partially submerged fracture model. } \\
\text { Temperature increasing, then } \\
\text { decreasing. Open side at top right. } \\
\text { Infrared temperature monitoring of } \\
\text { region above warmed region } \\
\text { performed. }\end{array}$ & $\begin{array}{l}\text { Finger flow penetrating warmed region. } \\
\text { Finger length decreasing with increasing } \\
\text { bath temperature. } \\
\text { The size of the condensation halo was } \\
\text { somewhat limited by the location of the side } \\
\text { vent. } \\
\text { Flow-formed saturated islands contained } \\
\text { numerous voids, condensation-formed } \\
\text { islands were completely filled. } \\
\text { Region of low temperature gradient } \\
\text { indicating vapor-liquid counterflow (heat } \\
\text { pipe behavior) was present in the } \\
\text { condensation halo region. }\end{array}$ \\
\hline
\end{tabular}




\begin{tabular}{|c|c|c|}
\hline $\begin{array}{l}14 \text { SFG/SFG } \\
\text { Fine Surface } \\
\text { Roughness }\end{array}$ & $\begin{array}{l}\text { More uniform than the SFG/FG } \\
\text { model with and aperture varying } \\
\text { from near zero to an estimated few } \\
\text { hundred microns. Sandblasted with } \\
240 \text { grit aluminum oxide for fine } \\
\text { surface roughness. Partially } \\
\text { submerged fracture model. } \\
\text { Temperature increasing, then } \\
\text { decreasing. } \\
\text { Infrared temperature monitoring of } \\
\text { region above warmed region } \\
\text { performed. }\end{array}$ & $\begin{array}{l}\text { Extremely narrow aperture made } \\
\text { introduction of pentane difficult due to } \\
\text { capillary and viscous controls. Very short } \\
\text { fingers penetrating warmed region. Finger } \\
\text { lengths decreased with increasing bath } \\
\text { temperature. } \\
\text { No heat-pipe behavior observed in thermal } \\
\text { images. }\end{array}$ \\
\hline $\begin{array}{l}\text { 15 Stripa } \\
\text { Replica }\end{array}$ & $\begin{array}{l}\text { Cast epoxy replica of natural } \\
\text { fracture in deep granite from Stripa } \\
\text { Mine, Sweden. } \\
\text { Infrared temperature monitoring of } \\
\text { region above warmed region } \\
\text { performed. }\end{array}$ & $\begin{array}{l}\text { Fingers, films, REEs, rapidly falling drops, } \\
\text { intermittent and flowing fingers observed. } \\
\text { Film and finger lengths decreased with } \\
\text { increasing bath temperature. } \\
\text { Heat-pipe behavior observed. }\end{array}$ \\
\hline $\begin{array}{l}\text { 16 Yucca } \\
\text { Mountain } \\
\text { (Fran Ridge } \\
\text { Replica/Rock) }\end{array}$ & $\begin{array}{l}\text { Cast epoxy replica of one face of a } \\
\text { natural fracture mated to the } \\
\text { fracture face of the rock from } \\
\text { sample obtained from SMF. } \\
\text { Infrared temperature monitoring of } \\
\text { rock surface performed. }\end{array}$ & $\begin{array}{l}\text { Liquid flowed in films and fingers with } \\
\text { films being predominant above the warmer } \\
\text { region. Imbibition into the dry rock limited } \\
\text { observation time and vapor-liquid } \\
\text { counterflow. } \\
\text { Heat pipe behavior not observed. }\end{array}$ \\
\hline
\end{tabular}

* SOG = Sandblasted Obscure Glass, FG = Flat Glass, SFG = Sandblasted Flat Glass

**REE- A rapid evaporation event occurs when a volume of liquid suddenly reaches its boiling point and rapidly evaporates on a time scale of tenths of a second, often forcing liquid droplets to move quickly away from the evaporation point.

These experiments were conducted by introducing pentane into the aperture of the fracture model or replica and applying heat to a portion of the model or replica. A light source was placed behind the model to allow for direct visualization of the liquid pentane in the fracture (Figure 3) in Experiments 1 - 15. In Experiment 16, the light source was placed in front of the replica to illuminate the fracture. Experiments were video taped using a JVC KY-F55BU camera with a JVC HZ-610MDU 6 - 60 mm motorized zoom lens with a Kenko No. 2 CloseUp filter and recorded on a Sony SVHS SVO-5800 video recorder with time coding providing temporal resolution of $1 / 30 \mathrm{~s}$. Pentane wets the air-glass and air-epoxy interface, in the same manner that water is generally assumed to wet air-mineral interfaces. Light is more easily transmitted through the fracture models and replicas where the surface is wet with the brightest regions occurring where the aperture is saturated with pentane. Two additional brightness levels are often visible in glass fracture models between the brightness level of the dry roughened glass (darkest) and the saturated aperture. These occur where films of pentane are present, and the different brightness levels may represent different pentane film thicknesses suited to multi-modal surface roughness; hence, different liquid saturations can be visually observed. Cases were also observed where different brightness levels occurred when a 
film was present on only one fracture face. In epoxy replicas, brighter regions also occur where films of pentane are present, however, no brightness differences in films have been distinguished.

Because of the transmission of light, flow patterns were directly observable without the addition of dye in transparent replicas and models. Flow patterns were established in the fracture models in a time frame that did not require completely sealing the model. Observations of flow path formation were made on several spatial scales, including the model scale (tens of centimeters), the finger scale (centimeters), and the finger structure scale (fractional centimeters).

\section{Observed Flow Behavior}

In Experiments 1 through 6,10 and 11, and 13 through 15, the fracture models and replicas were partially submerged in a glass tank into which temperature-controlled water was constantly supplied. The temperature of the water was set near but below the pentane boiling point at the beginning of the experiment and the model allowed to equilibrate with the water. After equilibration, pentane was introduced into the fracture model or replica aperture. The pentane seeped downwards, influenced by gravity, viscosity, and capillarity. In Figure 4, pentane seeps primarily downward, indicating the influence of gravitational force. When the pentane reaches the warmed region, even if the bath temperature is somewhat below the boiling point, a condensation halo may form in the cooler region above the heated bath. The temperature of the bath is increased over time to above the pentane boiling point to observe the drying out of the warmed region. In many cases, dry-out proceeds with liquid pentane in the warmed region evaporating out and condensing in the condensation halo. In the condensation halo, the pentane begins to travel downwards, either in films along the fracture wall or in intermittent or continuously flowing fingers that saturate the aperture (Figure 5). As the temperature of the warmed region approaches the pentane boiling point, pentane gas bubbles (formed by boiling) struggle to escape the bounds of saturated regions. Often this is relatively uneventful; however, rapid evaporation events (REEs) (Figure 6) have been frequently observed. In Figure 6, the encircled finger undergoes a REE. In a REE, a volume of pentane vaporizes quickly as it suddenly reaches its boiling point, rapidly expelling droplets of remaining pentane in many directions. In one case (Experiment 2), a rather large REE occurred during dry-out, sending a visible cloud of pentane upwards at a rate of about $30 \mathrm{~cm} / \mathrm{sec}$. Rate measurements were made from images captured from the time-coded video recordings.

Experiment 7 was conducted by attaching transparent disks to the fracture model through which water from the temperature controller could flow (Figure 7). The circular warmed regions were heated to well above the pentane boiling point, and pentane was introduced to 
the top of the system. This setup was designed to model, in an idealized fashion, the (partial) dry-out processes that are expected in the vicinity of emplacement drifts at Yucca Mountain. As the pentane reached the warmed region of the fracture model surrounding the heated disks, a condensation halo appeared surrounding the warmed region. Upon rapid introduction of pentane, pentane fingers seeped deeply into the warmed region (Figure 7). Following large seepage events, liquid flow occurred primarily by film drainage that did not penetrate deeply into the warmed region. When cooled to below the pentane boiling point, pentane films flowed through the warmed region.

Experiment 8 was conducted to determine whether the location of fingers was repeatable. The fracture model containing pentane was sequentially lowered into a constant temperature bath exceeding the pentane boiling point to predetermined locations and maintaining it at these locations for some time and recording the location of the fingers. The model was then sequentially raised to the same locations, again allowing some time at each location to observe where fingers formed. Major fingers formed in the same locations when the model was set at a particular height; however, the same number of fingers did not always form. Smaller fingers formed in different locations when the model was set to the same height. The amount of pentane in the system was not constant throughout the duration of the experiment due to evaporative loss. Pentane was added at intermittent intervals to replace the lost pentane. This loss and replenishment could have contributed to the different numbers of fingers.

In Experiment 9, the fracture model was allowed to equilibrate with warmed water exceeding the pentane boiling point prior to the introduction of pentane. Figure 8 shows that although pentane is introduced through the middle port, capillary forces draw the pentane horizontally to the left, after which a pathway downwards is encountered. Pentane is not as readily drawn to the right either because not as great a capillary pressure gradient exists in that direction, or because the aperture is more narrow towards the right than the left and viscous forces are comparatively greater. When the pentane penetrates the warmed region, it begins to boil and a condensation halo quickly forms above the warmed region. Fingers of the condensing pentane from this halo then formed in locations that were previously dry. The experiment was repeated with $1 / 2$ in. glass plates on either side of the fracture model to reduce the rate of heat transfer from the water bath to the fluid in the fracture. Fingers penetrated farther into the warmed region and were broader when the heat transfer was reduced (Figure 9). Thicker glass may tend to model more accurately the heat transfer through fractured rock where large rock masses exist between fractures. Temperature measurements of the portion of the fracture model above the water bath were made with an infrared camera (Inframetrics PM 200 Thermacam, SN 8954, $256 \times 256$ pixels) and will be discussed in the "Heat Pipe Development" section below.

Experiment 10 was conducted by placing $1.9 \times 2.5 \mathrm{~cm}$ Lexan strips at an angle across both sides of the fracture model (Figure 10). These strips reduced the rate of heat transfer between 
the thermal bath and the fracture model and from the fracture model to the atmosphere, and were intended to model rock thermal property heterogeneities. On heating, the region between the Lexan strips (Labeled "Region A" in Figure 10) was cooler than the surrounding model in the warmed region. Condensation occurred in this region, and fingers formed from the condensation. The apparent finger on the right side was not the result of this condensation, but of capillary flow from the bottom upwards. The region between the Lexan strips above the warmed region was warmer than the surrounding area, thus condensation rates were reduced. As the experiment progressed, the heating heterogeneity caused shortening of one finger which had formed in previous experiments (Figure 11), and lengthening of an adjacent finger. This lengthening is not visible in Figure 11. On cooling, the Lexan strips caused Region A to remain warmer than the surroundings, thus hindering condensation and film flow (Figure 12).

The fracture model used in Experiment 11 was constructed using sandblasted (80-grit) obscure glass. Epoxy barriers were placed on one face of the glass at an angle of about 20 degrees from horizontal to form funnel-like structures and the plates were pressed together and cemented around the edges leaving vents on the top as in previous experiments. Funnellike structures are of interest because they have been observed in soils (Kung, $1990 \mathrm{a}$ and b) and are capable of focusing flow into localized preferential paths. Seepage through the model was impacted by the presence of these barriers (Figure 13). A condensation halo formed under the right barrier and in vertical regions outside the funnel from which fingers formed. Pentane saturated the aperture in the center of the funnel obstructing vertical gas flow, forcing gas to flow in pathways outside of the funnel structure. The longest fingers flowed from the pathway between the lower barriers (Figure 14). Temperature measurements made of the upper part of the fracture model are discussed in the "Heat Pipe Development" section below.

The fracture model used in Experiment 12 was composed of two sheets of sandblasted (80grit) flat glass cemented together with three thicknesses of $0.254-\mathrm{mm}$ brass shims around the edges, providing a nominal aperture of $0.76 \mathrm{~mm}$. This models a wide vertical fracture with a few contact points. Upon introduction, pentane flowed straight downwards rapidly to the model bottom. The warmed region of the model was near the pentane boiling point, and a condensation halo appeared soon after injection. Because of the wide aperture, pentane was held in films on the fracture faces; no saturated islands formed. Following the evaporation of all of the pooled pentane in the warmed region, steady films flowing downwards into the warmed region were observed (Figure 15). Additional volumes of pentane were added resulting in the condensation halo extending further both vertically upwards and downwards. When enough pentane was added so that the films covered the entire non-warmed region, drops of pentane condensed on the model top and fell downwards with speeds on the order of $50 \mathrm{~cm} / \mathrm{s}$, slowing in the dry, warmed region, but frequently reaching the model bottom. 
Experiment 13 was conducted with a model composed of two sheets of sandblasted (240-grit) obscure glass. A region 12 centimeters long on the right side, $5.5 \mathrm{~cm}$ above the warmed region, was left open. This caused a rapid loss of pentane (compared with other experiments) and tended to keep the height of the condensation halo below the vent. Longer fingers formed on the right side near the vent. This is likely due to pentane vapors being forced under a pressure gradient from their point of evaporation towards the atmospheric pressure boundary at the side vent. Condensation of this vapor would occur as the pentane moved towards the vent resulting in the longer fingers.

Experiment 14 was conducted with a model composed of two sheets of sandblasted (240-grit) flat glass. This model had the narrowest aperture of all models investigated, and thus viscous flow resistance was the highest and capillary effects strongest. After the boiling temperature of pentane was reached, very short fingers penetrated the warmed region. Saturated islands of pentane were present throughout the upper region, with flow-formed islands having a porous structure, and condensation formed islands being completely filled.

Experiment 15 was conducted using an epoxy fracture replica with dimensions $21.8 \times 30.3 \times$ $\sim 3.7 \mathrm{~cm}$, made from both faces of a natural fracture in a granite core obtained from the Stripa mine in Sweden. This particular fracture and replicas thereof have also been used in a series of isothermal water flow experiments at ambient temperatures (Geller, et al., 1996). The replica faces were mated and sealed together with epoxy like the fracture models, leaving three vents on the top (Figure 16). When releasing the confining pressure used in gluing the faces together, the faces came apart on the right and bottom sides. These were re-glued without applying confining pressure thus the aperture towards the right and bottom is likely to be generally larger than at the top and left. All phenomena observed in the glass fracture models were observed in this experiment, including film flow, continuous rivulet flow, intermittent rivulet flow, REEs, drops falling rapidly through the fracture, and the development of a heat pipe. Finger and film length also decreased with increasing temperature. The falling drops occurred on the right side where the aperture was greater, with condensation occurring higher in the replica, presumably at a location of contact or small aperture. A feature referred to as a microfracture intersected the plane of the warmed region at an angle. Downward flow in the location of the microfracture was altered if the flow was slow. Rapidly moving drops passed the microfracture with their course unaltered. On the left side, where the aperture was narrower, a cell of boiling pentane existed in the warmed region, fed by pentane flowing down the microfracture and by a continuously and later intermittently flowing finger from a saturated island above the cell. This boiling cell was present at bath temperatures well above the pentane boiling point. The thermal conductivity of epoxy is much less than that of glass $\left(0.2 \mathrm{Wm}^{-1} \mathrm{~K}^{-1}\right.$ vs. $\left.1.4 \mathrm{Wm}^{-1} \mathrm{~K}^{-1}\right)$, perhaps more accurately modeling heat transfer in large fractured rock masses. 
Experiment 16 was conducted using a replica of one fracture face and the corresponding rock face from a natural fracture from a sample obtained from Fran Ridge (near Yucca Mountain). The replica was made by attempting to saturate the rock with water prior to making a mold with the RTV compound to prevent imbibition of the RTV into the matrix. Saturating with water was done instead of using a mold release compound in an attempt to provide a more accurate impression of surface roughness, and to leave the rock surface topography and chemistry as pristine as possible. Saturation was not complete, however, and some RTV imbibed into the rock, altering its wettability from initially very water wetting to water repelling. Visual inspection suggests that the replica has approximately the same roughness as the rock surface.

Prior to the introduction of pentane, the rock was heated using heating tapes set at between 65 and $100^{\circ} \mathrm{C}$. After six hours, temperature measurements indicated that only small portions of the rock face exceeded the pentane boiling temperature, so for about 20 minutes a heat gun was used in addition to the heating tape. Temperature measurements then indicated that a large area of the rock fracture face was above the pentane boiling point. The epoxy face was affixed to the warm rock and allowed to equilibrate for 8 minutes (Figure 17), after which the replica was removed and a thermal image of the rock surface was obtained. The epoxy face was replaced, and eight 1- to 3- milliliter volumes of pentane were introduced with two additional disassemblies, rock temperature measurements, and observations made. Due to evaporation and imbibition attributed to the large size and dryness of the rock $(\sim 130 \mathrm{~kg})$ and the amount of heat added, each addition of pentane was visible for only about one minute. This may be representative only of small flows in heated, very dry fractures such as intermittent flows very near the heat source, and is not considered to be representative of all liquid flow in heated fractures where flow rates, water content, and relative humidity may be much greater. Better matching of liquid volumes to rock size and heat content will be attempted in future experiments.

\section{Heat Pipe Development}

Of the sixteen experiments listed in Table 1, thermal imaging of the fracture model or replica above the warmed region was performed in seven. Thermal imaging of the portion of the model submerged in the water has not been performed. Spatially resolved near-aperture (model or replica surface) temperatures were monitored using an infrared camera. The temperatures recorded by the infrared camera are of the front glass or epoxy surface. These temperatures are indicative of the temperatures within the aperture, but somewhat lower due to convective heat loss to the atmosphere. Liquid-vapor counterflow (heat-pipe conditions) is indicated by regions of low temperature gradient. Thermal images are presented in Figures 18 - 24. In these figures, temperatures are represented by colors, with a scale presented underneath. The scales are unfortunately sparse due to the data acquisition method; however, 
low temperature gradients, shown as uniform color regions or slowly changing colors indicative of heat-pipe conditions, are clearly visible in the images. The temperature scale corresponding to each image is different to account for high and low temperatures perceived by the camera. Heat-pipe conditions were observed in five of the seven experiments in which near-aperture temperatures were monitored.

The initial temperature distributions in all these experiments with no pentane in the aperture show a steep temperature gradient near the interface between the warmed and ambient regions (Figure 18). This steep gradient is expected for heat transfer from an extended surface or fin, where in the limit of an infinite one-dimensional fin, the normalized excess temperature goes as $\mathrm{e}^{-\mathrm{mx}}$, where $\mathrm{x}$ is distance and $\mathrm{m}$ is a function of the relative importance of conductive and convective heat transfer (Incropera and DeWitt, 1981). With pentane in the aperture and the bath temperature exceeding the boiling point, large regions of low temperature gradient have been observed, indicating the formation of a heat pipe. An example is shown in Figure 19.

The shape of the heat pipe region is strongly affected by the structure of the aperture. In Figure 19, the green protrusions on the left and right sides indicate vertical pentane vapor pathways in these locations. The photo image to the left shows corresponding conduits free from saturated islands of pentane in these locations. Towards the center and adjacent to these conduits are saturated islands of pentane, indicated in the thermal image by the darker green and cyan (cooler). The central bright green region contains darker green spots that correspond to the locations of pentane islands saturating the aperture. In Experiment 11, heat-pipe development was strongly affected by the impermeable barriers (Figure 20). Pentane vapor was forced to travel vertically on the left and right sides of the model due to the impermeable barriers and liquid saturation in the center of the funnel structure. These warmed regions are indicated by the brighter green color. In the center, the model is cooler, indicating that liquid flow is predominant there. The shape of the heat-pipe region in Experiment 13 was influenced by the presence of the large vent on the upper right side (Figure 21). Newly vaporized pentane in this experiment was pushed towards the right boundary where the pressure was ambient, producing a bulge in the condensation halo and longer fingers on the right. The most uniform heat-pipe region was found in Experiment 12 (Figure 22). Due to the wide aperture, pentane was present only in films on the fracture walls. The orange region shows a very nearly constant temperature. The size of the heat-pipe region was larger when more pentane was present in the model: In Experiment 14, the aperture was very narrow which severely restricted liquid and vapor flow and limited heat pipe development (Figure 23). An uneven heat pipe formed in the Stripa fracture replica (Experiment 15) that was much more predominant on the right side. This is because the aperture was wider there providing less viscous resistance to flow (Figure 24). No heat pipe was observed in rock/replica Experiment 16. Insufficient liquid was present in the system for the partial rock saturation needed to investigate this phenomenon. Thermal images indicate 
some rock cooling where the pentane evaporation occurred, however, thermal conductivity heterogeneities may also explain the observed temperature distributions.

\section{Discussion}

\subsection{Liquid Flow in Fractures Under Conditions of Partial Saturation and Thermal Drive: Implications for Fast Liquid Flow Paths}

Three types of liquid flow have been visually observed and are distinguishable in the fracture models. These are described here as continuous rivulet flow, intermittent rivulet and drop flow, and film flow. In the laboratory experiments, continuous rivulet flow occurred during the initial rapid introduction of pentane into the models and replicas. In this flow, the gravitational forces greatly exceed the capillary and viscous forces, which would tend to stabilize the pentane in the fracture. The direction of flow responds to the gravitational and capillary forces controlled by aperture heterogeneity. Continuous rivulet flow would occur in geologic media in locations where a constant supply of water was present, either due to infiltration or to the confluence of many, smaller flows at a heterogeneity. Intermittent rivulet flow occurs when there is only a slight imbalance between the stabilizing capillary forces and the destabilizing gravitational forces. These events occur when liquid is held in saturated islands, which are roughly in equilibrium with destabilizing forces. When additional fluid is added to these saturated islands, the destabilizing forces exceed the stabilizing capillary forces, and liquid from the saturated island flows in response to the imposed forces. This flowing liquid may contact other saturated islands and destabilize them, adding volume to the flow. Intermittent rivulet flow will likely occur in geologic media any time the rate of water seepage into a region exceeds the capacity for the water to flow onwards via film flow. Drop flow is an extreme example of intermittent rivulet flow. This occurs when liquid accumulates at a contact point above a wide aperture. When a sufficient volume collects such that gravitational force exceeds the capillary force, a drop breaks off and falls. In wide vertical apertures, it is conceivable that liquid may fall freely without contacting the fracture walls. Film flow occurs when the aperture is large. The films discussed here are on the order of tens of microns thick (Tokunaga and Wan, 1997); much thicker than thin adsorbed water films which are on the order of tens to a hundred angstroms thick (Gee, Healy, and White, 1990). These thick films move on the fracture walls in response to gravitational forces and capillary forces imposed by the surface roughness. This type of flow may be the slowest of the three observed types and seems to be incompatible with rivulet flow when the fracture wall temperature exceeds the boiling temperature. Film flow may be the dominant flow mechanism transporting condensate to saturated islands, and dominant under low flow conditions where the amount of water present exceeds the amount that would be present due to sorption and capillary-held water in equilibrium with groundwater. All of these conditions may be present at Yucca Mountain. 
In all experiments performed, fingers penetrated some distance into the warmed region. In some experiments, films also penetrated into the warmed regions, primarily in wider aperture regions of fractures. The depth of penetration of both films and fingers decreased with increasing temperature of the water bath (Figures 25 - 27). The average finger length and the variability of the finger length are displayed in Figures 26 and 27 for Experiments 9 (thick glass) and 10. No theoretical analysis has yet been developed to attempt to scale finger and film penetration information determined under experimental conditions to conditions expected at Yucca Mountain. Development of these theoretical analyses and scaling relationships is expected to be a priority in FY 1998.

Because of the somewhat friable nature of the welded tuff within the ESF and the mining techniques used, fracture samples from the ESF large enough for experimentation purposes are not presently available. Fractured Topopah Spring Tuff samples recently obtained from Fran Ridge are suitable for experimentation purposes, and experiments are currently being conducted on these samples and their replicas. The natural surface roughness of fractures within the ESF ranges from nearly table-top smooth to roughly half-centimeter steps. This roughness range was experimentally accounted for by heterogeneities in fracture models due to imperfections in the glass manufacture, manufactured heterogeneities in obscure glass, and heterogeneities imparted by uneven sandblasting. Large-scale surface roughness was modeled by using two different roughnesses of glass: flat and obscure glass. Two sandblasting grits were used to provide different small-scale surface roughness. Impermeable barriers were placed in a fracture model to observe the effects of focusing flow, and uneven heating was used to simulate heterogeneous heat transfer. Experiment 15 was performed using a replica of a natural fracture from the Stripa Mine in Sweden. The variability in fracture features within this replica induced all the phenomena observed in the experiments using glass models. Experiment 16 was conducted using an epoxy replica of one fracture face mated to the actual opposing rock-fracture face of a sample from Fran Ridge near Yucca Mountain. Heterogeneities and boiling conditions influenced flow and liquid imbibition into the rock. The high degree of small-scale surface roughness caused rapidly spreading pentane films on both the epoxy replica and the rock surface.

Pentane has been introduced into vertical fracture models containing regions both above and below the pentane boiling point, and all regions below the pentane boiling point. The temperature ranges used in the experiments generally bracketed the pentane normal boiling point $\left(36.1^{\circ} \mathrm{C}\right)$ by several degrees. This allowed for observation of phenomena across this range. Water has not been used as the working fluid, and hence the effect of ionic strength has not been investigated. The relative importance of gravity has been investigated by using fracture models with different apertures rather than by inclining the model. Drop flow in subvertical fractures would be different than in vertical fractures, but other phenomena observed are more strongly influenced by viscosity due to narrow apertures, and would likely be similar. In horizontal fractures, only minimal vapor-liquid counterflow would be 
expected, which would reduce the heat pipe effect. This was modeled by a fracture model with a very narrow aperture. Other effects due to subvertical inclinations are not expected to be large in narrow aperture fractures, due to the high capillary and viscous forces encountered. These effects may be more pronounced in wider aperture fractures and will be considered in future experiments.

Parameters such as the enhanced diffusion coefficient and the magnitude of buoyant gas flow have not been quantified in this work. In this work, it is believed that advection is the predominant gas flow mechanism under the conditions investigated because of the rapid evaporation of pentane (local production of pentane gas). Measurement of both buoyant gas flow and enhanced diffusion would require advection to be relatively unimportant. The enhanced binary diffusion coefficient is poorly understood in porous media where it has been studied for more than 40 years (Cass, Campbell, and Jones, 1984). The conditions for which it exists in a partially saturated fracture have not yet been identified.

\subsection{Conditions Conducive to Forming Heat Pipes}

The general conditions necessary for heat pipe formation include (1) a region at a temperature exceeding the liquid boiling point (evaporation zone), (2) adequate space for vapor and liquid counterflow, (3) a region cooler than the liquid boiling point (condensation zone), and (4) a driving force for liquid return to the evaporation zone. In all of these experiments, the driving force for liquid return is gravity. Horizontal flow was observed in some cases within the condensation halo due to capillary forces, but the liquid was ultimately returned to the warm region by gravity. In one of the five experiments where heat pipes were observed (Experiment 12), liquid return was in films, in the other four experiments, liquid return to the evaporation zone was primarily in fingers. Within the condensation halo (condensation zone), fingers and films were responsible for liquid flow. Large horizontal capillary pressure gradients present within fractures and on fracture surfaces due to dryout may contribute in the long run to the amount of water present above the heated drifts available for reflux and flow in fast paths.

In Experiment 12 (Figure 22), good heat pipe conditions exist, and the condensation halo is uniform. The wide aperture provides for minimal interference between the liquid and vapor, and the liquid return is due to gravity. In Experiment 11 (Figure 20), gas flow is hindered by the impermeable barriers and liquid saturation in the model center. Similarly, the liquid flow through the funnel center was hindered by the increased pressure in the model bottom. Saturated islands, such as those in Figure 19, may act like impermeable barriers to the vapor transport, while at the same time the liquid may be flowing.

No heat pipe was observed in Experiment 14. In this experiment, the aperture was small, and viscous resistance controlled liquid flow. The rate at which pentane flowed into the warmed region, evaporated and condensed, was not large enough such that thermal images registered 
significant deviation from the original condition. The condition for adequate space for vapor-liquid counterflow was not met in this experiment.

\section{Conclusions}

Emplacement of heat-generating nuclear waste packages in a partially saturated environment such as Yucca Mountain is expected to give rise to complex two-phase (liquid-gas) flow phenomena with phase change (boiling and condensation). Of particular interest are heatdriven flows in fractures, which could cause "fast" migration of water and solutes along localized-preferential pathways. The objective of the current project is to obtain a better understanding of the relevant phenomena through laboratory-scale experimentation under controlled and monitored conditions.

We have studied thermally driven flows in a variety of laboratory fracture specimen, using glass plates of different small- and large-surface roughness, an epoxy replica of a natural rock fracture, and an actual rock fracture. The typical scale of the experiments was $20-30$ $\mathrm{cm}$. Pentane, with a boiling point of $36.1{ }^{\circ} \mathrm{C}$, was used as volatile fluid instead of water to facilitate the experiments. Flow behavior was observed visually, and spatially-resolved temperature monitoring was performed. Our initial experiments have demonstrated the following phenomena: boiling and condensation; formation of dry-out zones; flow funneling, focusing, and bypassing; localized-preferential flow of liquid in nominally superheated regions; capillary-driven flow; and film flow. The presence of heat-pipe processes (vaporliquid counterflow) was inferred from observations of extended regions with very nearly isothermal conditions.

The project is continuing. Future work will attempt to explore flow in a broader variety of fracture specimen, with special emphasis on actual rock fractures from Yucca Mountain. Different flow geometries will be explored, including non-vertical fractures. An effort will be made to not only use pentane, but to also set up experiments with water as the working fluid. Quantitative analysis of fluid flow and heat-transfer mechanisms will be made, and issues of scale-up to conditions at Yucca Mountain will be considered. Close integration will be sought with ongoing in situ heater experiments at Yucca Mountain, and with mathematical modeling studies of thermo-hydrologic behavior.

\section{Data Collected}

In order to record visible phenomena, all laboratory experiments have been video taped, thus, data have been collected in video form. Video and "TGRAM" format recording of thermal images have also been made for Experiments 9 and $11-16$. Table 2 provides a catalogue of recordings made. These recordings are considered preliminary at this time, and planning is 
underway for editing and producing a video for distribution. Production of the video is expected to be completed in FY 1998. Film penetration depth data displayed in Figure 25 were submitted on 14 April with data tracking number LB970400123122.001. Finger length data displayed in Figures 26 and 27 are included with data tracking numbers LB970600123122.001 and LB970600123122.002.

\begin{tabular}{|c|c|}
\hline Experiment & Video Recording ID \\
\hline 1SOG/FG & 1/29/97 SOG/FG \\
\hline 2 SOG/FG & SOGFG 1/30/97 \\
\hline 3SFG/FG & FGXSFG 1/30/97 \\
\hline 4 SOG/SOG & 2/4/97 SOGXSOG \\
\hline 5SOGISOG & $2 / 11 / 97$ SOG/SOG \\
\hline 6 SFGTSFG & SFGxSFG $2 / 27 / 97$ \\
\hline 7 SOGTSOG & SOG/SOG Circular 2/28/97 \\
\hline 8 SOG/FG Finger Location Repeatability & 3/20/97 Repeatability \\
\hline $\begin{array}{l}\text { 9SFG/SFG Wall Thickness/Heat Pipe } \\
\text { Development }\end{array}$ & $\begin{array}{l}\text { 3/26/97 SFGXSFG w/ Temperatures } \\
\text { 3/27/97 SFG/SFG Thick } \\
\text { Thermal Tape ID: } \\
\text { 3/26 SFG/SFG Thin Temps } \\
\text { 3/27/97 SFG/SFG Thick Temps }\end{array}$ \\
\hline 10 SFG/SFG Non-uniform Heating & 4/15/97 SFG/SFG w/LEXAN \\
\hline 11 SOG/SOG Impermeable Barriers & $\begin{array}{l}\text { 4/17/97 SOG/SOGII Heterogeneous } \\
\text { Thermal Tape ID: } \\
\text { 4/17 SOG/SOGII Heterogeneities Temps }\end{array}$ \\
\hline 12 SFG/SFG Wide Aperture & $\begin{array}{l}\text { 5/12/97 Wide Aperture SFG/SFG } \\
\text { Thermal Tape ID: } \\
\text { 5/12/97 Wide Aperture SFG/SFG temps }\end{array}$ \\
\hline 13 SOG/SOG Fine Surface Roughness & $\begin{array}{l}\text { 5/13 SOG/SOG } 240 \text { uneven } \\
\text { Thermal Tape ID: } \\
\text { 5/13 SOG/SOG } 240 \text { uneven temps }\end{array}$ \\
\hline 14 SFG/SFG Fine Surface Roughness & $\begin{array}{l}\text { 5/13/97 SFG/SFG240 } \\
\text { Thermal Tape ID: } \\
\text { 5/13/97 SFG/SFG240 temps }\end{array}$ \\
\hline 15 Stripa Replica & $\begin{array}{l}\text { 5/30/97 Stripa Replica } \\
\text { Thermal Tape ID: } \\
\text { 5/30/97 Stripa temps }\end{array}$ \\
\hline 16 Yucca Mountain (Fran Ridge Replica) & $\begin{array}{l}\text { 6/5/97 Fran Ridge II } \\
\text { Thermal Tape ID: } \\
\text { 6/5/97 Fran Ridge II temps }\end{array}$ \\
\hline
\end{tabular}

Table 2. Laboratory Experiments and Video Recordings.

\section{Quality Assurance Status}

Data collected and referenced herein were collected under the YMP Quality Assurance Program. They are recorded in scientific notebooks YMP-LBNL-TJK1 and YMP-LBNLTJK2 and associated images. Calibration data for the infrared camera are contained in YMPLBNL-JSW-1.2. Data used to compile Figure 2 come from recognized sources (see page 4 of this report) and as existing data do not need to be qualified. Conclusions drawn from this work are based on qualified data. 


\section{Acknowledgments:}

This work was supported by the Director, Office of Civilian Radioactive Waste Management, U.S. Department of Energy, through the Memorandum Purchase Order EA9013MC5X between TRW Environmental Safety Systems, Inc. and the Emest Orlando Lawrence Berkeley National Laboratory, under Contract No. DE-AC03-76SF00098.

The technical reviews by Yvonne Tsang and Ardyth Simmons and the quality assurance review by Don Mangold and Vivi Fissekidou were greatly appreciated.

\section{References}

Buscheck, T.A. and J.J. Nitao, April 26-30, 1993. The analysis of repository-heat-driven hydrothermal flow at Yucca Mountain, Proceedings, Fourth High Level Radioactive Waste Management International Conference, Las Vegas, NV.

Cass, A., G.S. Campbell, and T.L. Jones, 1984. "Enhancement of thermal vapor diffusion in soil," Soil Science Society of America Journal, Vol. 48, No. 1, pp. 25 - 32.

CRWMS M\&O (Civilian Radioactive Waste Management System, Management and Operating Contractor), 1997. Single Heater Test Interim Report (BABEAF000-01717-69000001 REV00), Yucca Mountain Site Characterization Project Milestone.

Flint, A., J.A. Hevesi and L.E. Flint, 1996. Conceptual and numerical model of infiltration for the Yucca Mountain area, Nevada. Water Resources Investigation Report, U.S. Geological Survey, Denver, CO.

Gee, M.L., T.W. Healy, and L.R. White, 1990. "Hydrophobicity effects in the condensation of water films on quartz," Journal of Colloid and Interface Science, Vol. 140, No. 2, pp. $450-465$.

Geller, J.T., G. Su, and K. Pruess, 1996, Preliminary studies of water seepage through roughwalled fractures, Lawrence Berkeley National Laboratory report LBNL-38810, Berkeley, CA.

Gentier, S., 1986. Morphologie et comportement hydromèchanique d'une fracture naturelle dans un granite sous constrainte normale, Ph.D. Thesis, Univ. D' Orlèans, France.

Incropera, F.P. and D.P. DeWitt, 1981. Fundamentals of Heat Transfer, John Wiley and Sons.

Kung, K-J.S., 1990. "Preferential flow in a sandy vadose zone: 1. Field observation," Geoderma, Vol. 46, pp. 51 - 58. 
Kung, K-J.S., 1990. "Preferential flow in a sandy vadose zone: 2. Mechanisms and implications," Geoderma, Vol. 46, pp. 59 - 71.

Lide, D.R., 1990. Handbook of Chemistry and Physics, 71st Edition, CRC Press, Inc.

Meyer, C.A., R.B. McClintock, G.J. Silvestri, and R.C. Spencer, Jr., 1993. ASME Steam Tables, Thermodynamic and Transport Properties of Steam, Sixth Edition.

Persoff, P. and K. Pruess, 1995. "Two-phase flow visualization and relative permeability measurement in natural rough-walled rock fractures", Water Resources Research, Vol. 31, No. 5, pp. 1173 - 1186.

Pruess, K., 1997. "On vaporizing water flow in hot sub-vertical rock fractures", in press in Transport in Porous Media.

Pruess, K. and Y. Tsang., March 1994. Thermal modeling for a potential high-level nuclear waste repository at Yucca Mountain, Nevada, Lawrence Berkeley Laboratory Report LBL35381 .

Rossini, F.D., K.S. Pitzer, R.L. Amett, R.M. Braun, G.C. Pimentel, 1953. Selected values of Physical and Thermodynamic Properties of Hydrocarbons and Related Compounds, Published for the American Petroleum Institute by Carnegie Press, Carnegie Institute of Technology.

Su, G., 1995. Water Infiltration and Intermittent Flow in Rough-Walled Fractures, Masters Thesis, Department of Civil Engineering, University of California, Berkeley.

Tokunaga, T.K. and J. Wan, 1997. "Water film flow along fracture surfaces of porous rock," Water Resources Research, Vol. 33, No. 6, pp. 1287 - 1295.

Vargaftik, N.B., 1975. Tables on the Thermophysical Properties of Liquids and Gases in Normal and Dissociated States, Second Edition, John Wiley and Sons, Inc.

Wark, K., 1977. Thermodynamics, Third Edition, McGraw-Hill Book Company.

Welty, J.R., C.E. Wicks, and R.E. Wilson, 1984. Fundamentals of Momentum, Heat, and Mass Transfer, Third Edition, John Wiley and Sons. 


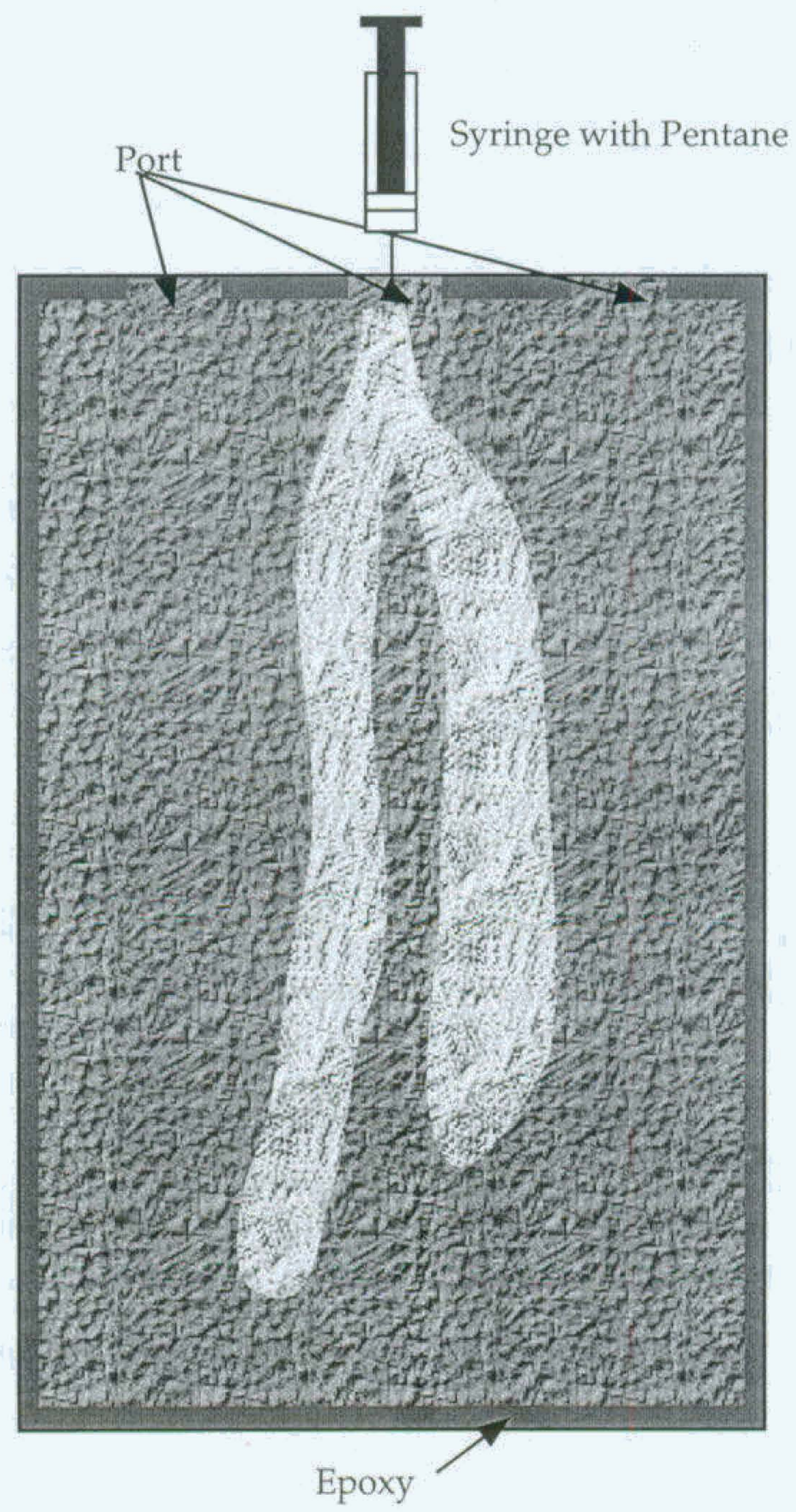

Figure 1. Glass fracture model. 


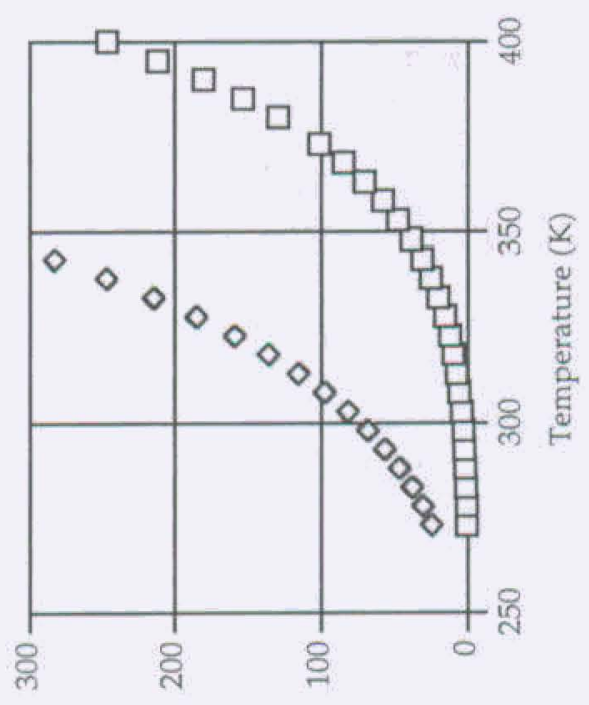

$\left(\mathrm{e}_{\mathrm{d}}\right.$ ) amssar $\mathrm{x}_{\mathrm{d}} \operatorname{Iode}_{\Lambda}$

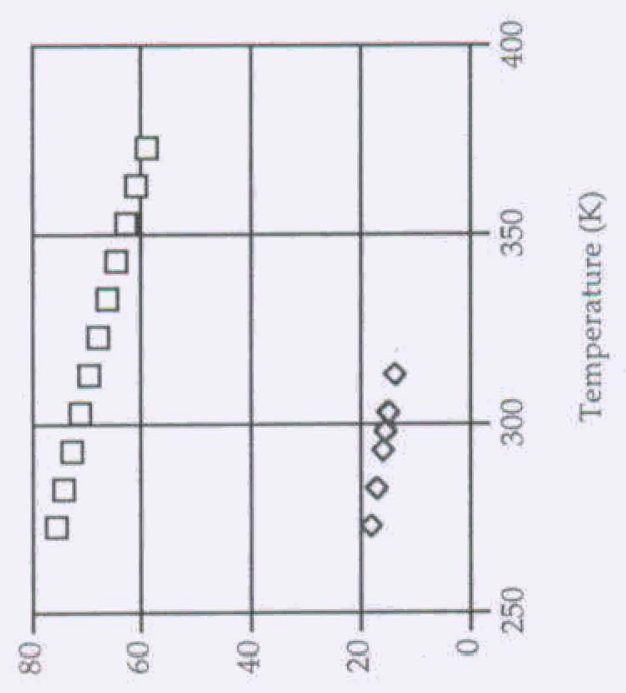

(u/Nu) uotsua $L_{L}$ apejuns
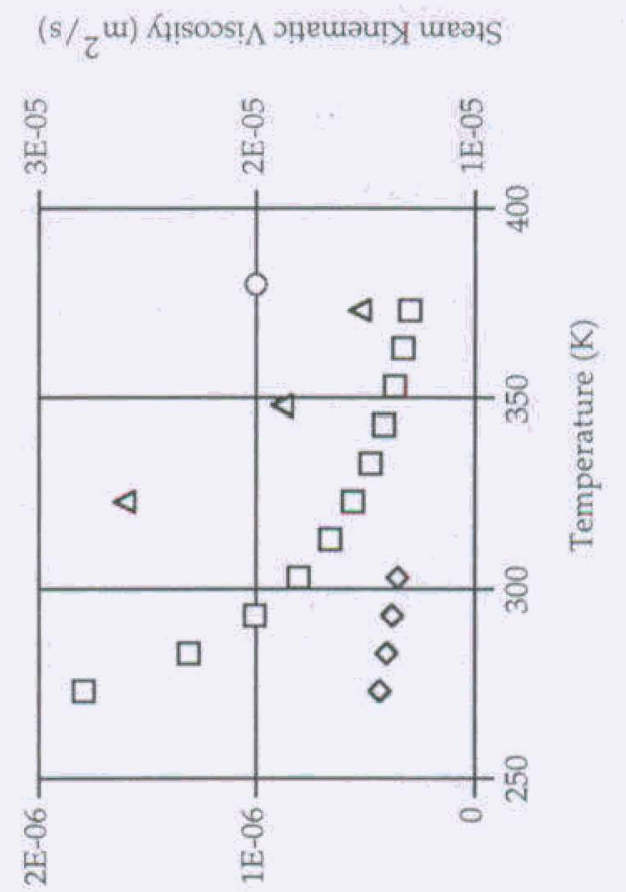

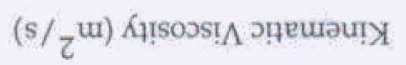

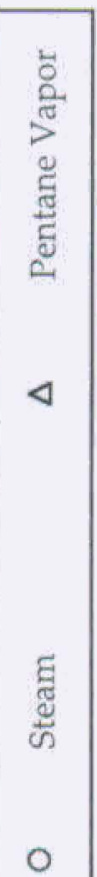

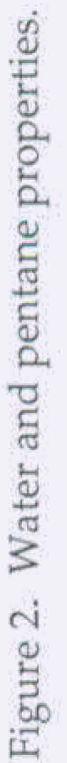




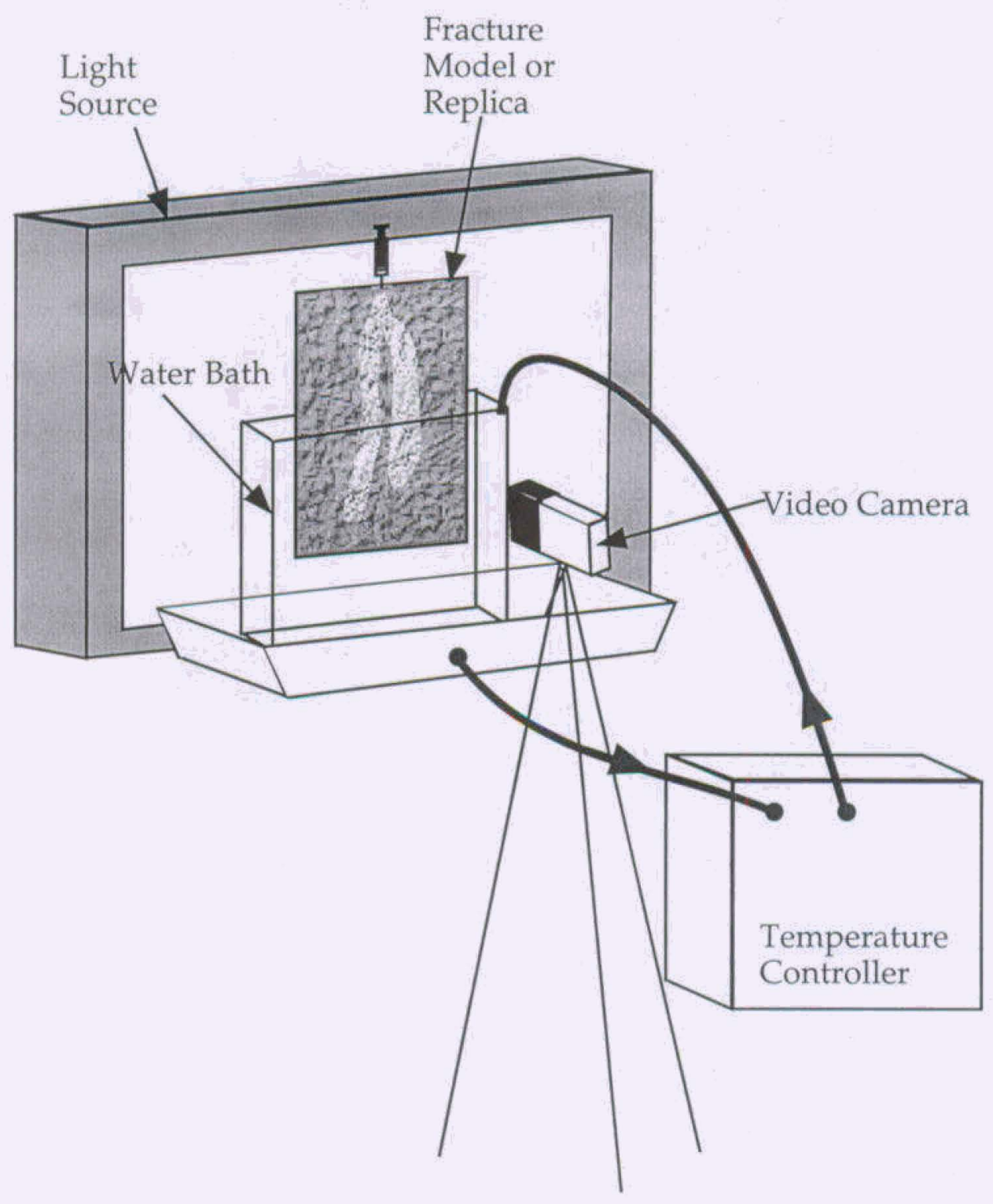

Figure 3. Experimental setup. 


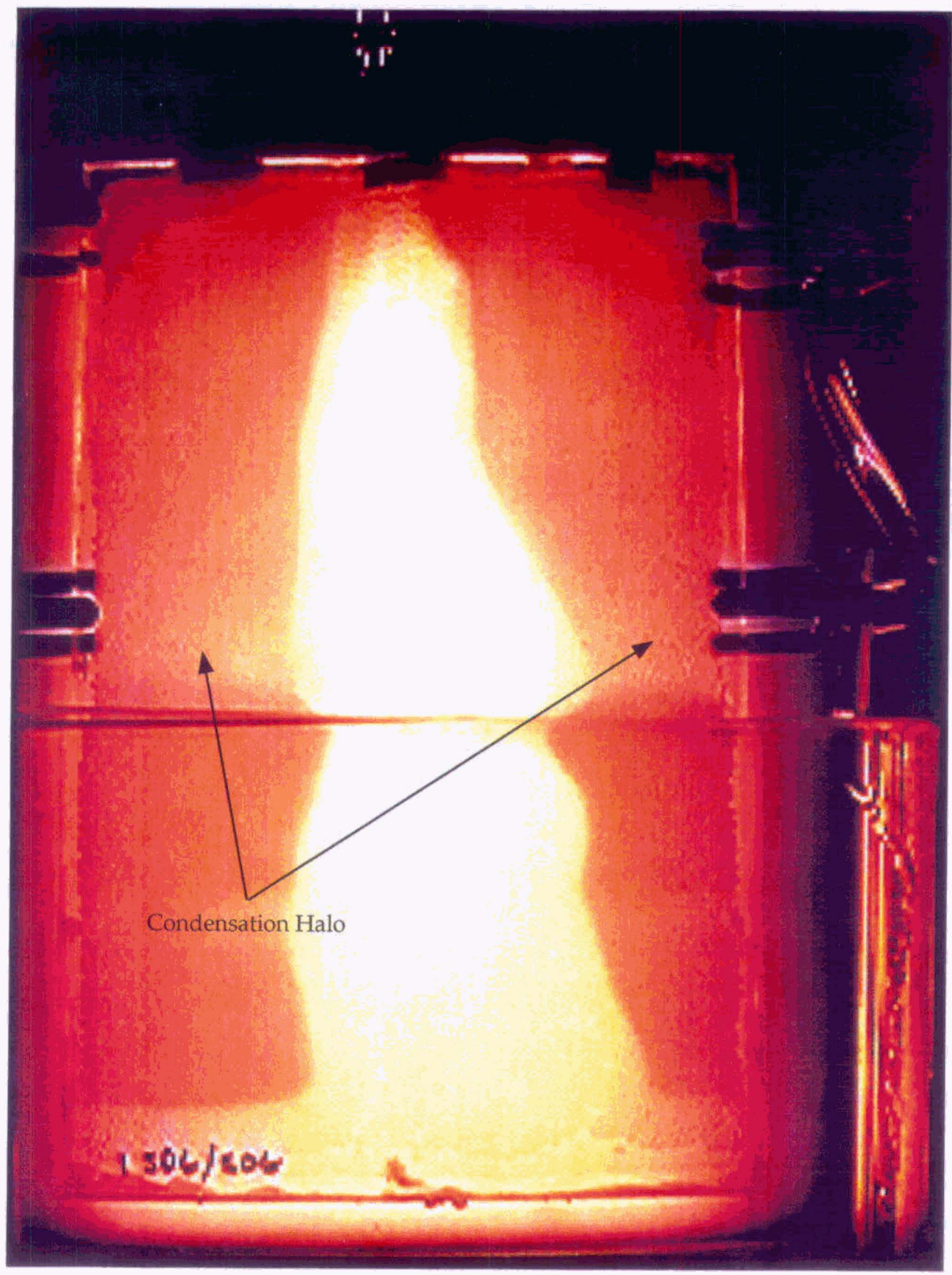

Figure 4. Condensation halo forming. Experiment 4, $33.8^{\circ} \mathrm{C}<\mathrm{T}_{\text {bath }}<34.4^{\circ} \mathrm{C}$ 


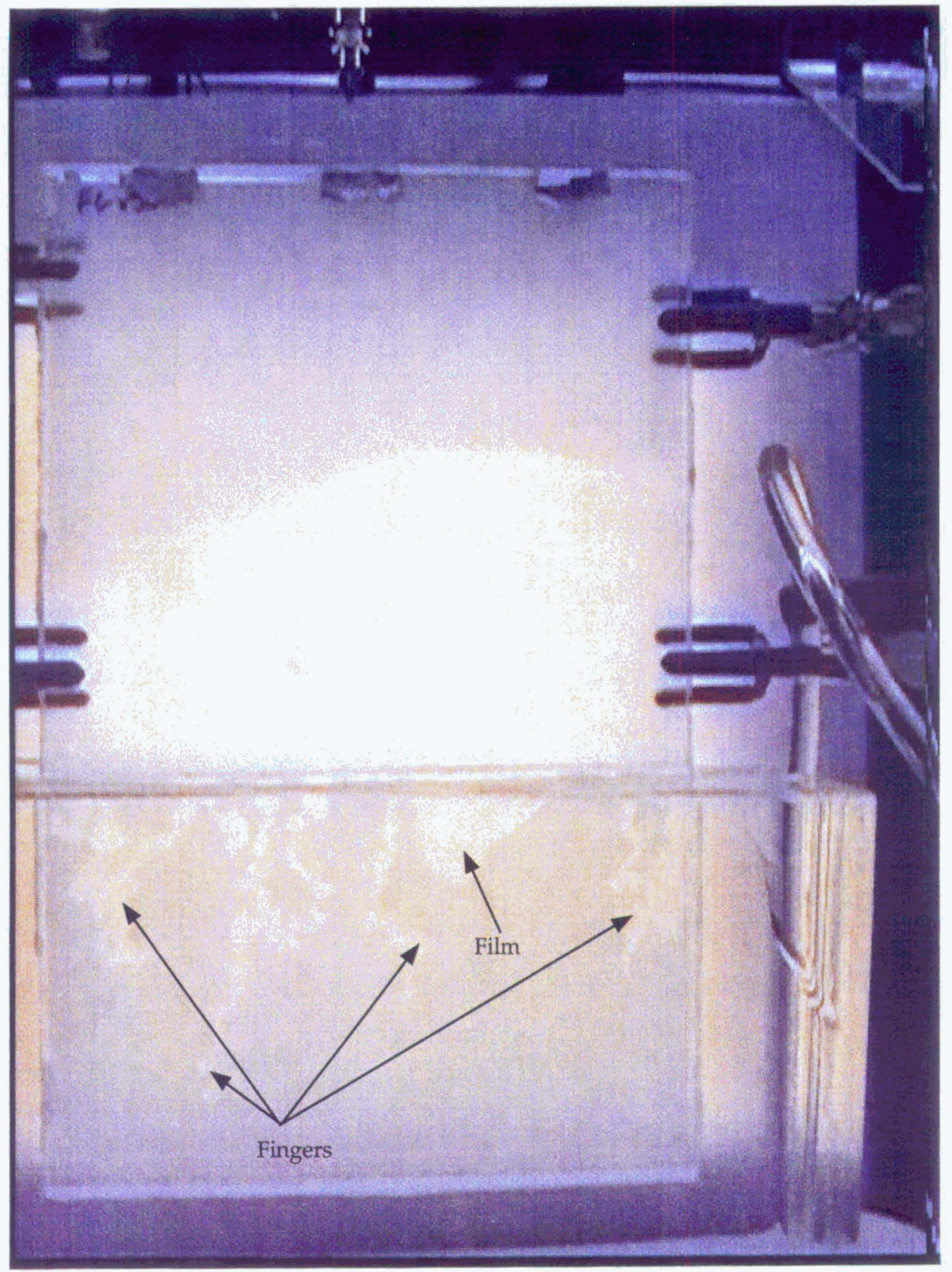

Figure 5. Fingers and films. Experiment $1,37.2^{\circ} \mathrm{C}<\mathrm{T}_{\text {bath }}<37.6^{\circ} \mathrm{C}$ 

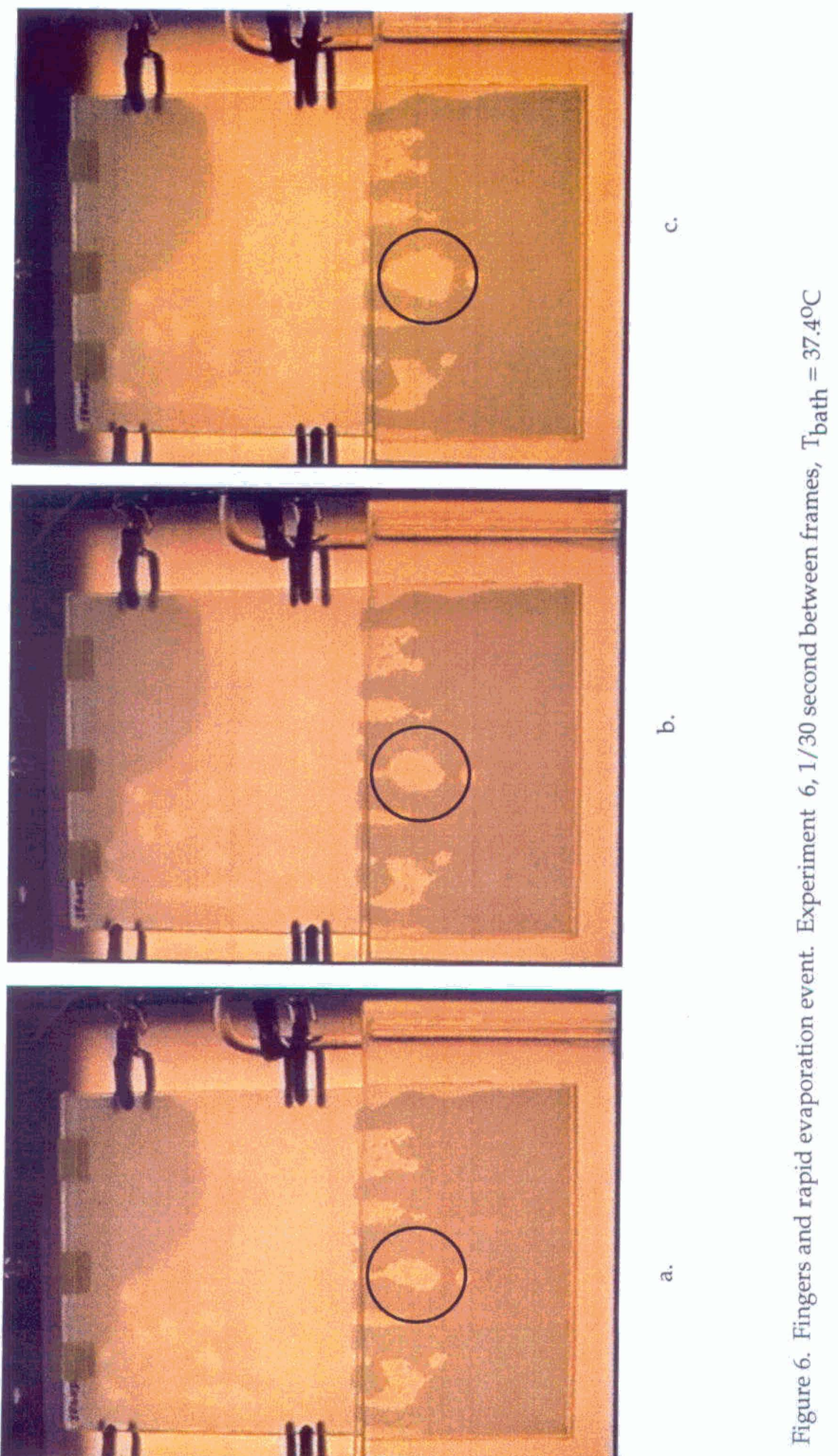

के

D

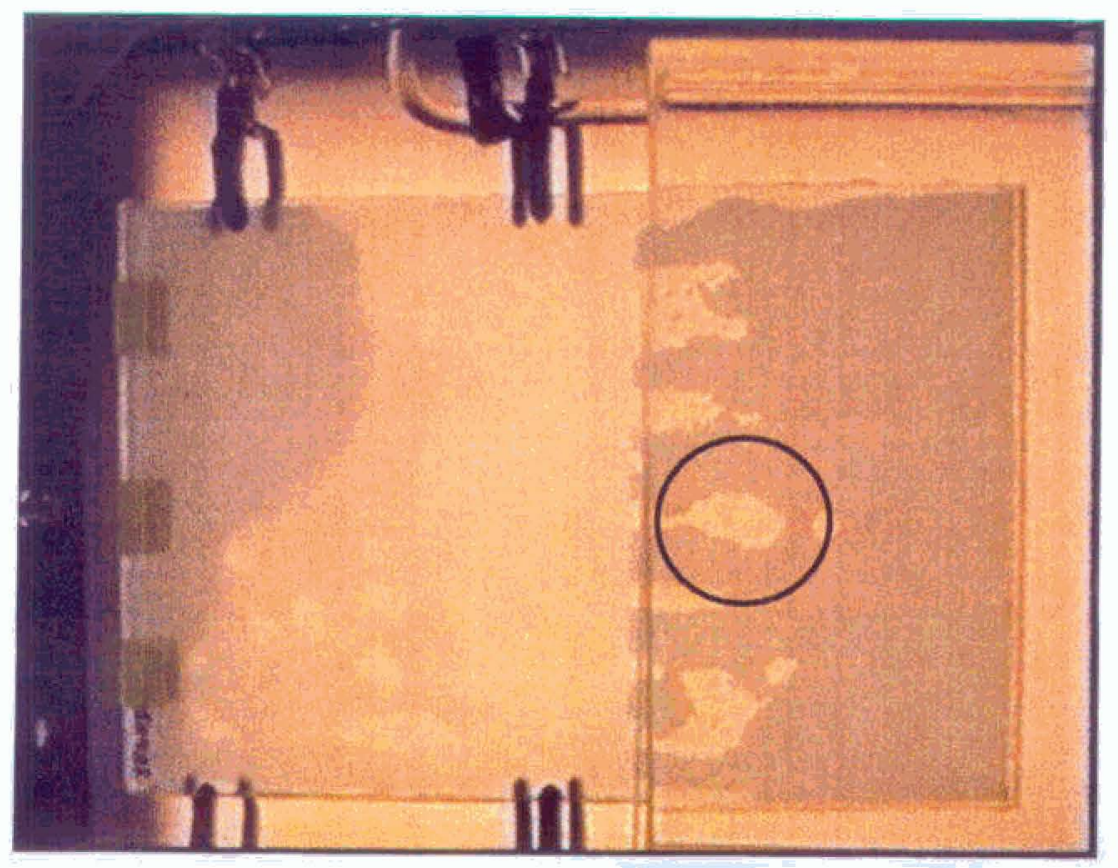

त 

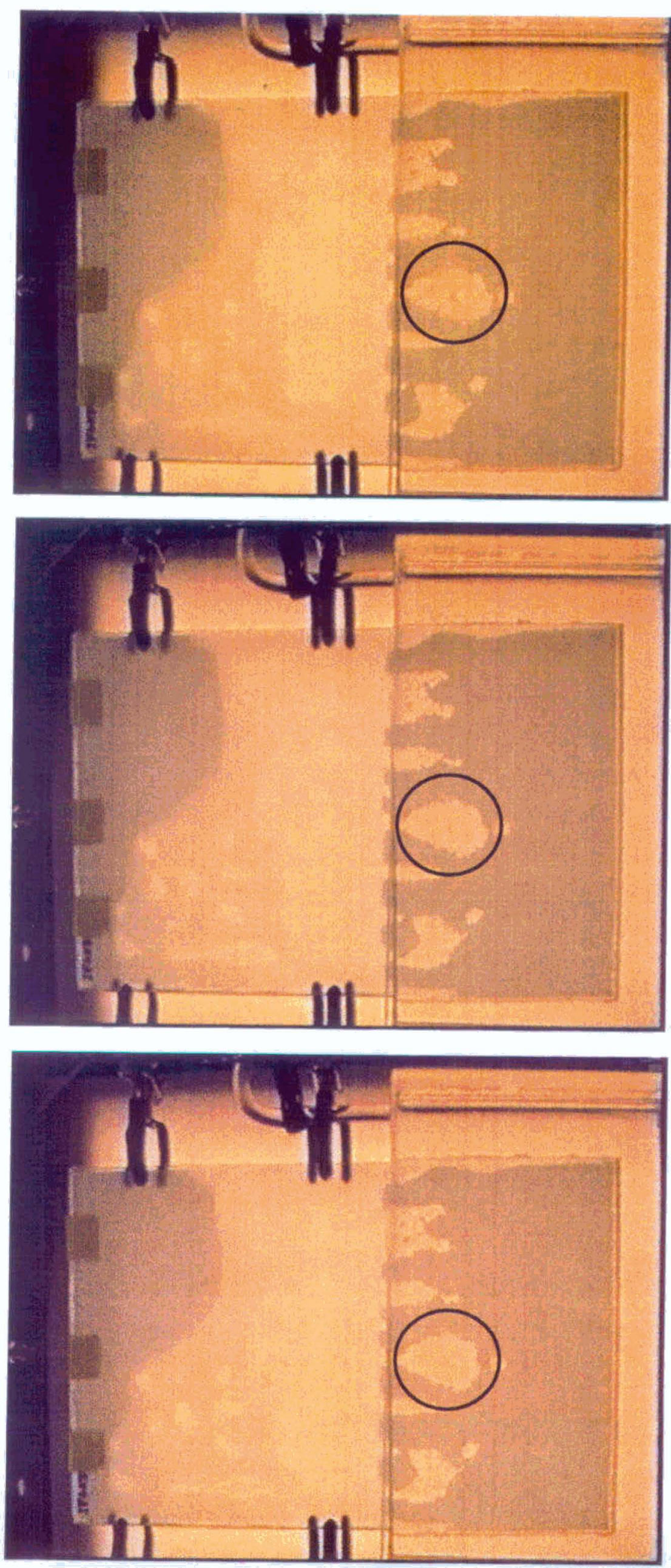

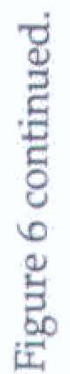




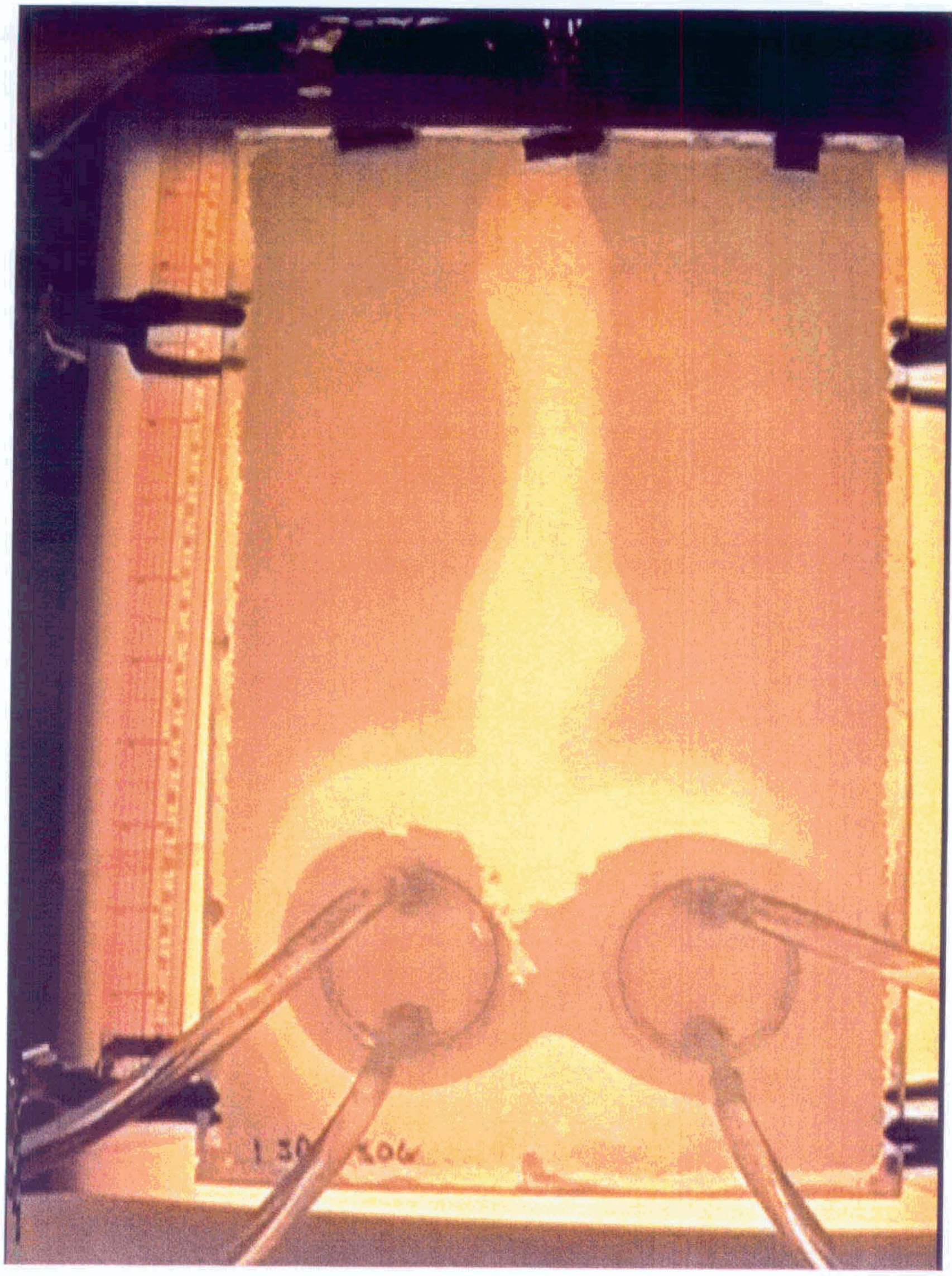

Figure 7. Finger between and through warmed circles. Experiment 7, $\mathrm{T}_{\text {reg }}=50.6^{\circ} \mathrm{C}$ 


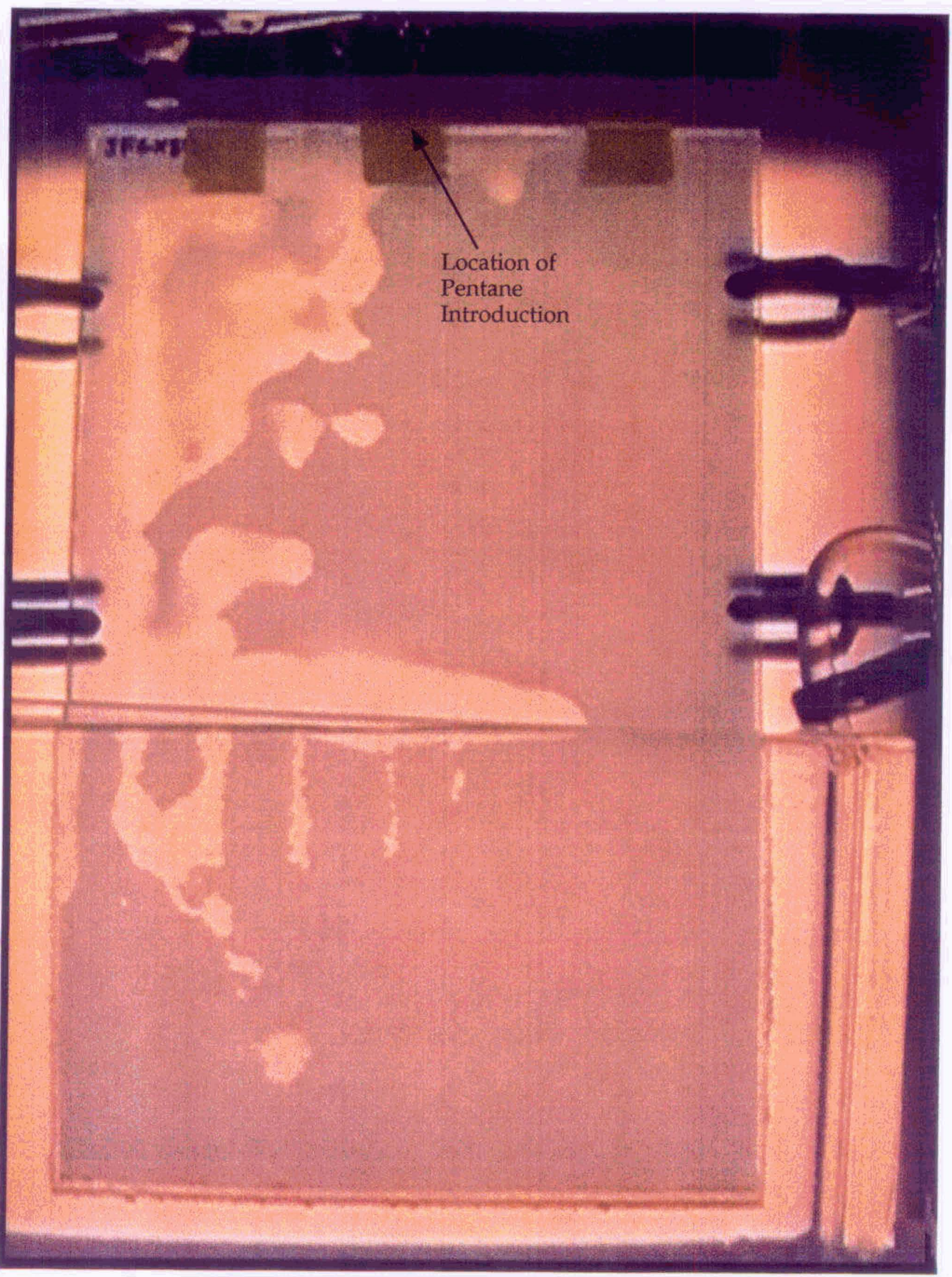

Figure 8. Infiltration and condensation halo formation. Experiment 9, $\mathrm{T}_{\text {bath }} \sim 36.5^{\circ} \mathrm{C}$ 


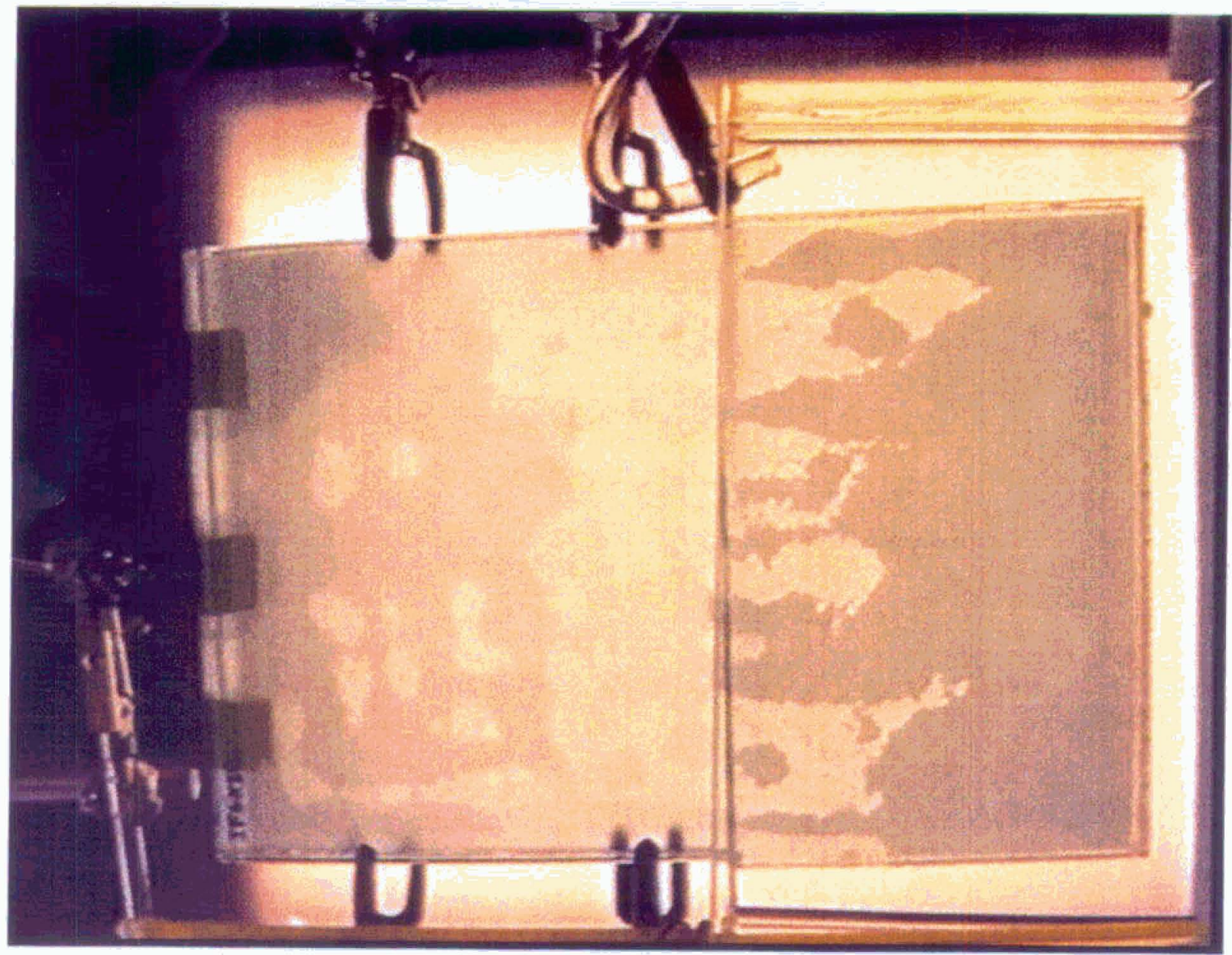

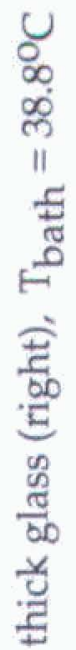

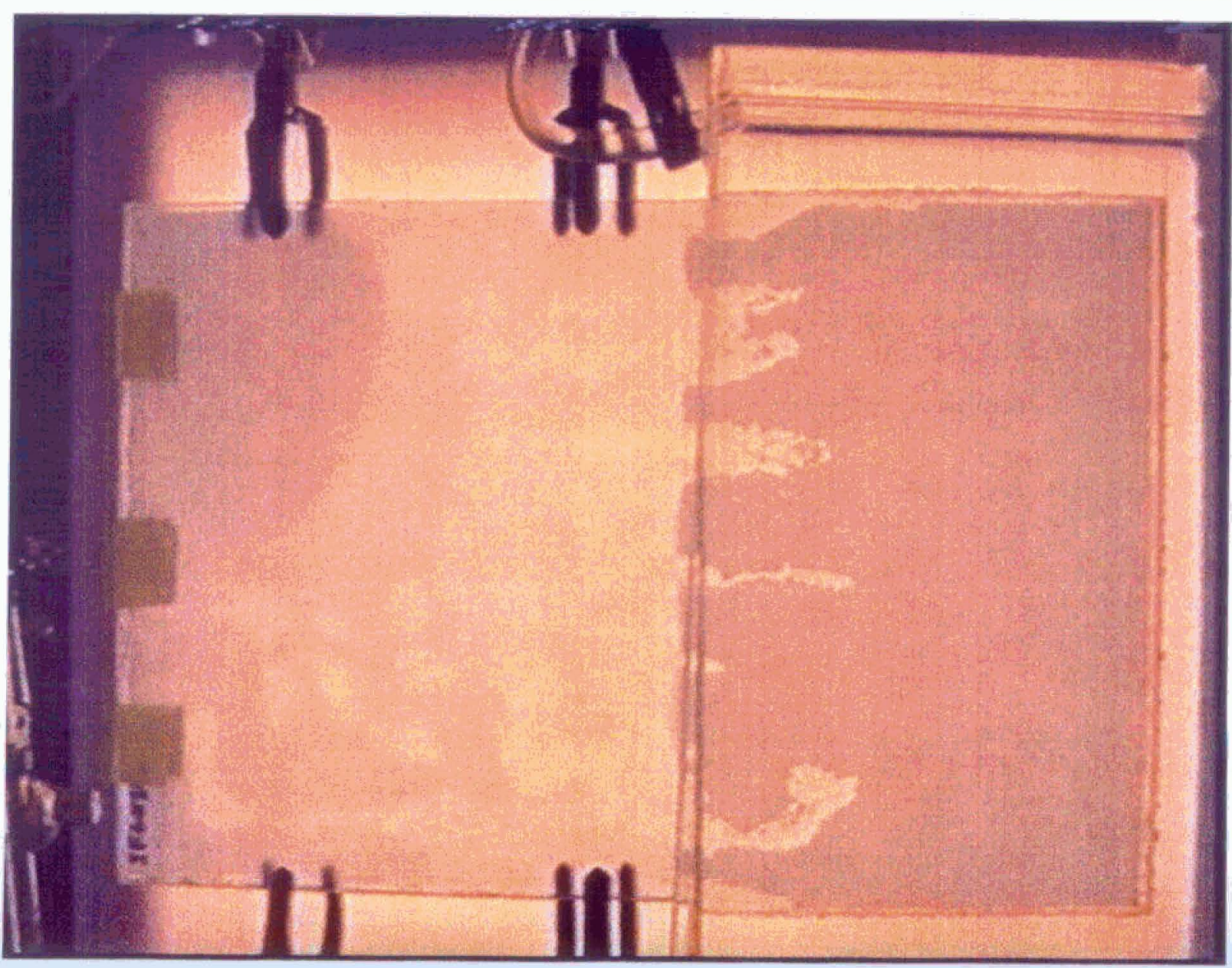

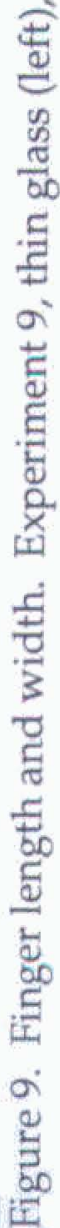




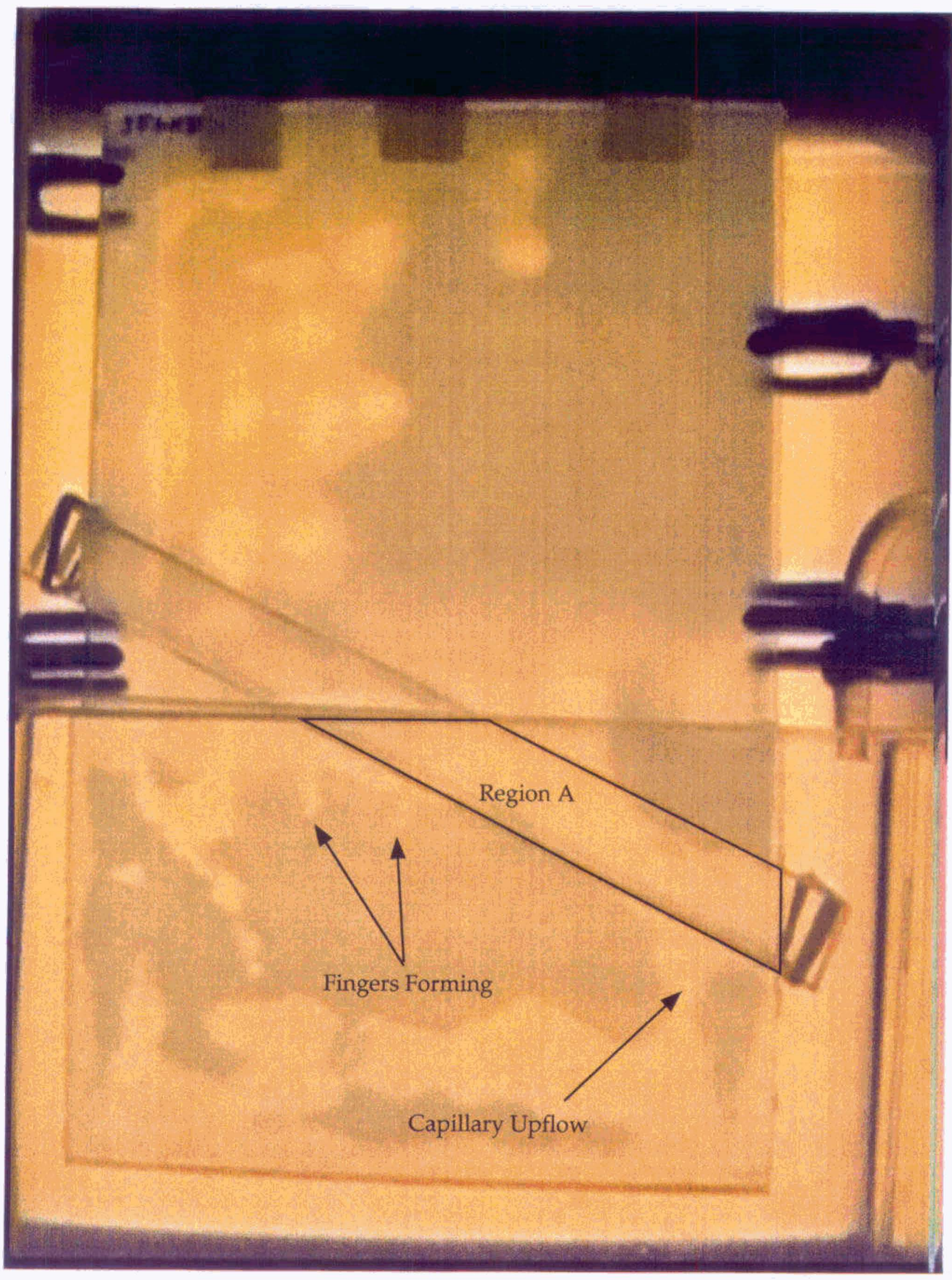

Figure 10. Fingers forming in model with Lexan strips on heating. Experiment 10, $35.6^{\circ} \mathrm{C}<\mathrm{T}_{\text {bath }}<36.4^{\circ} \mathrm{C}$ 


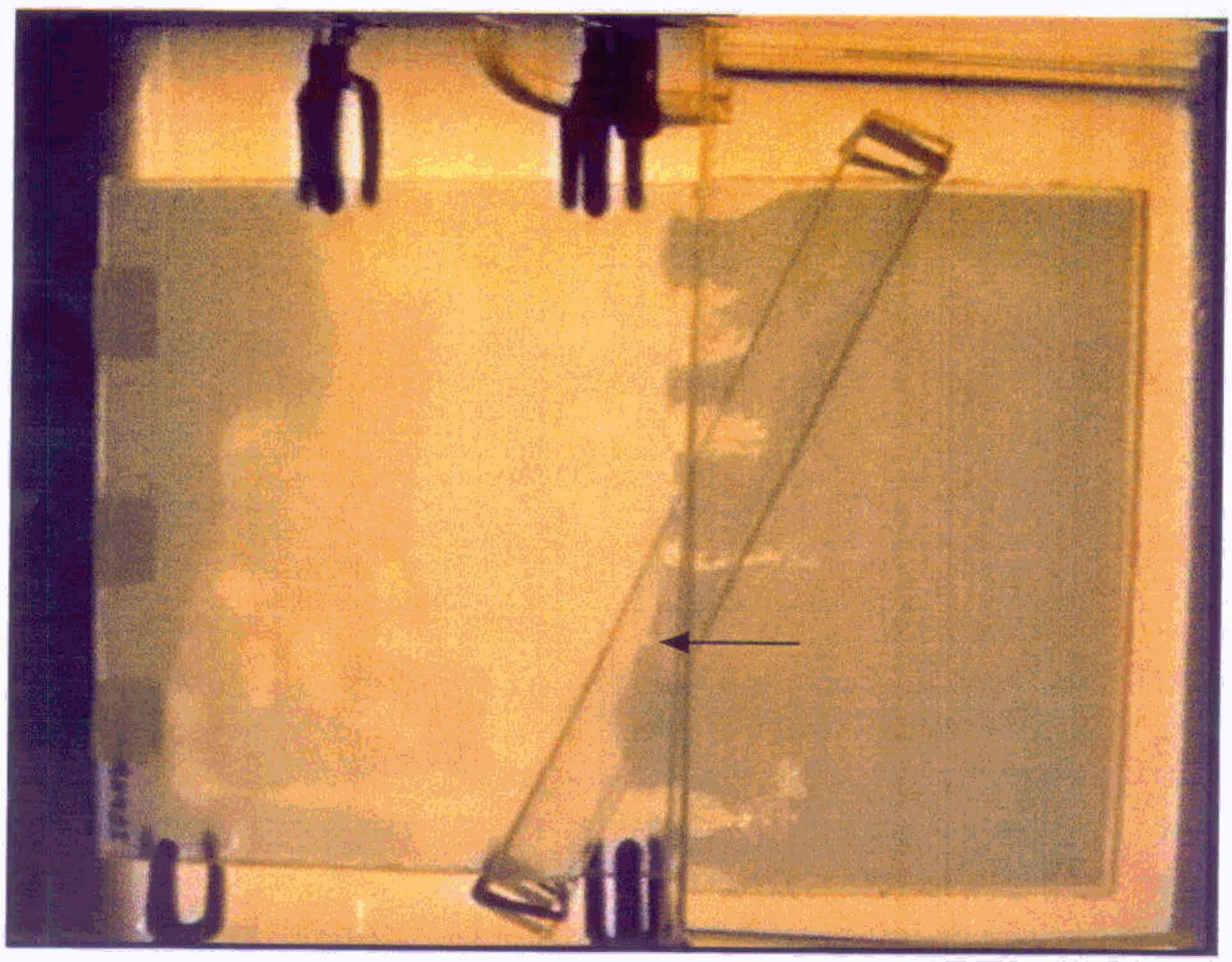

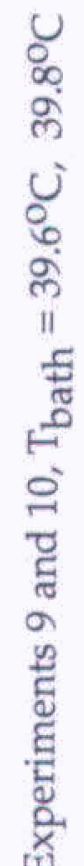

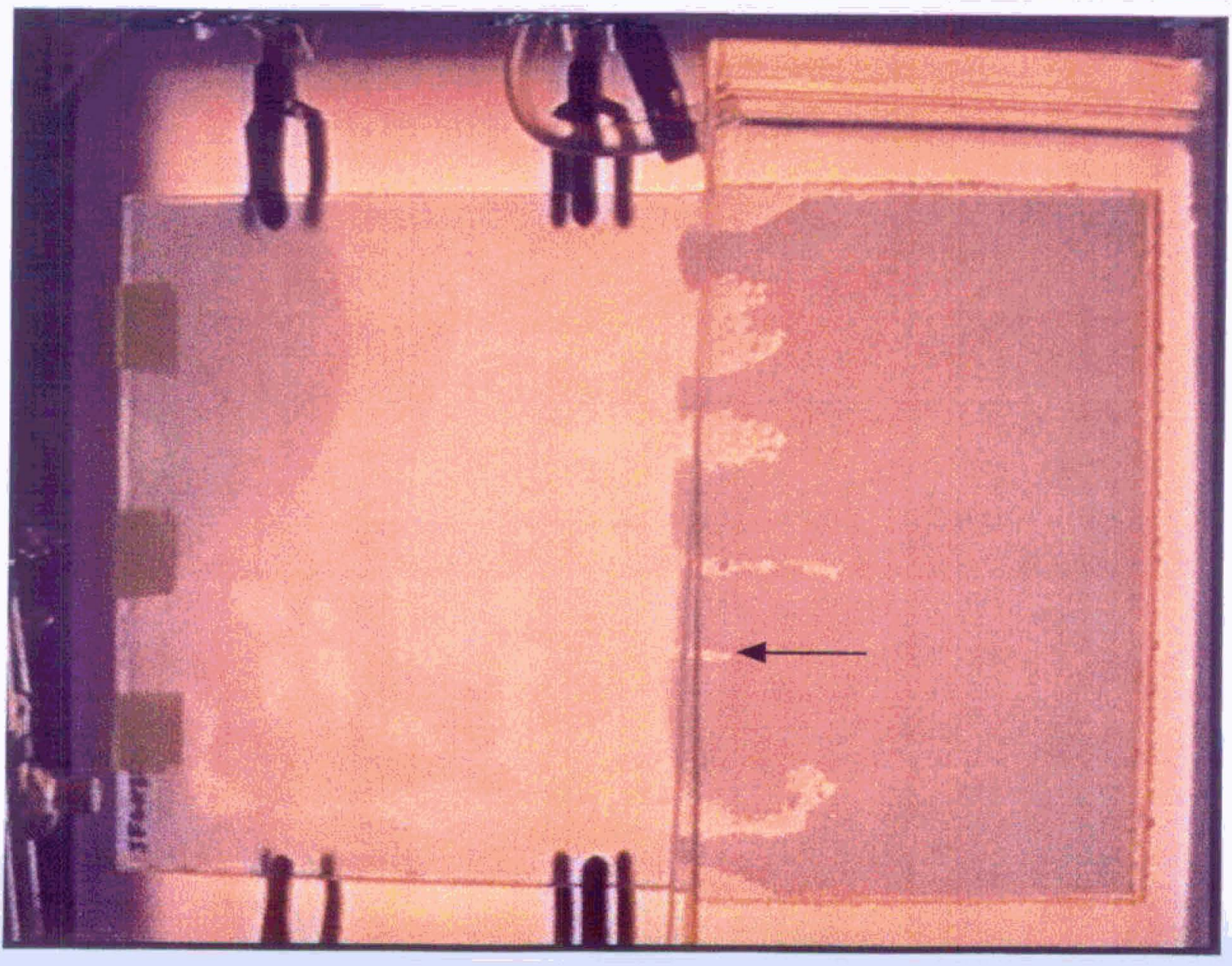

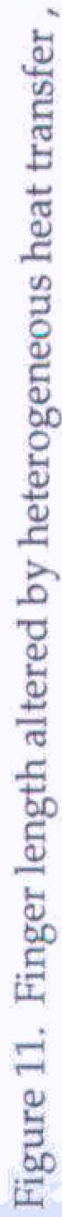




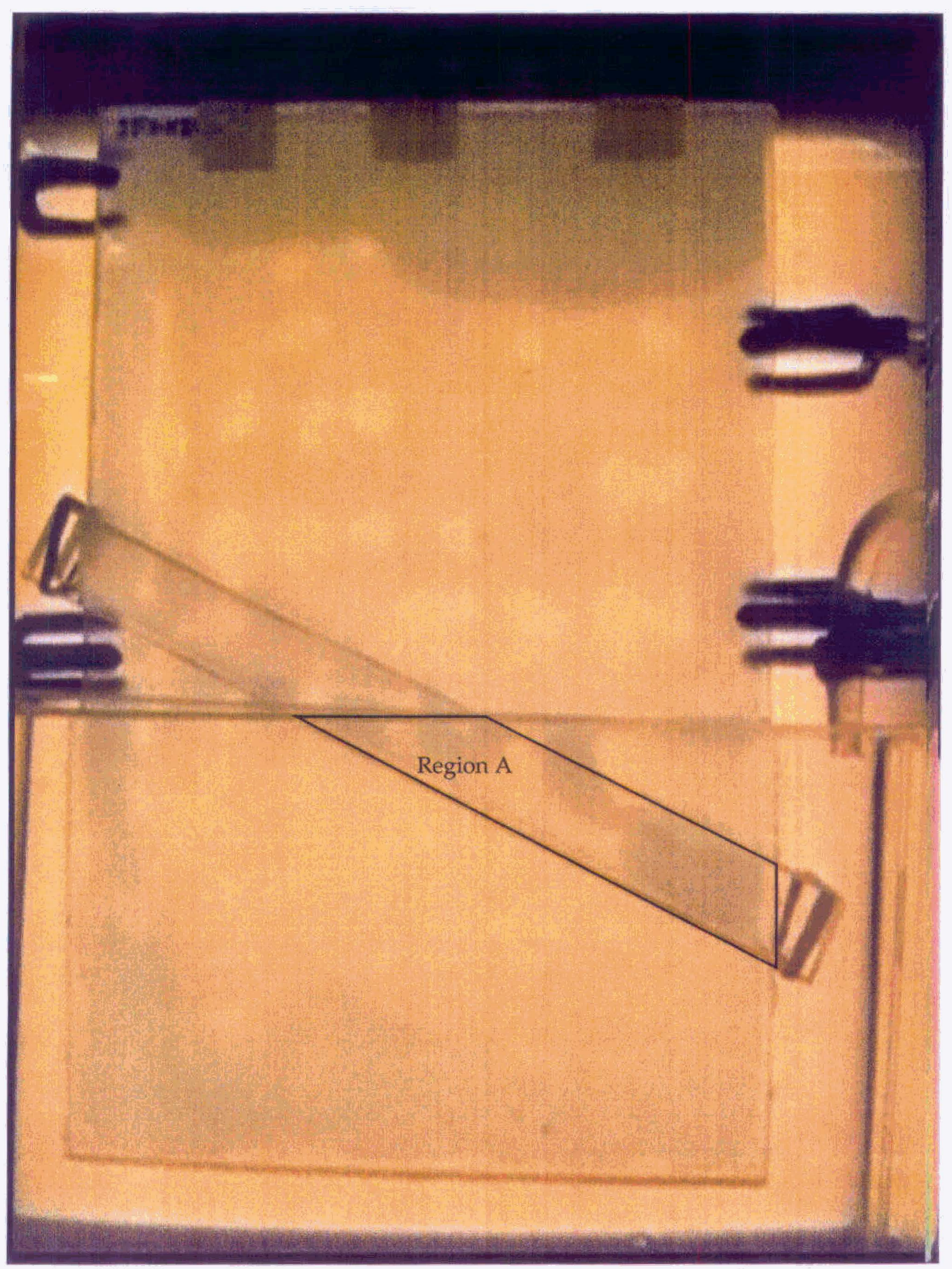

Figure 12. Film development and hindered flow in Region A. Experiment 10, $\mathrm{T}_{\text {bath }}=$ $35.2^{\circ} \mathrm{C}$ 


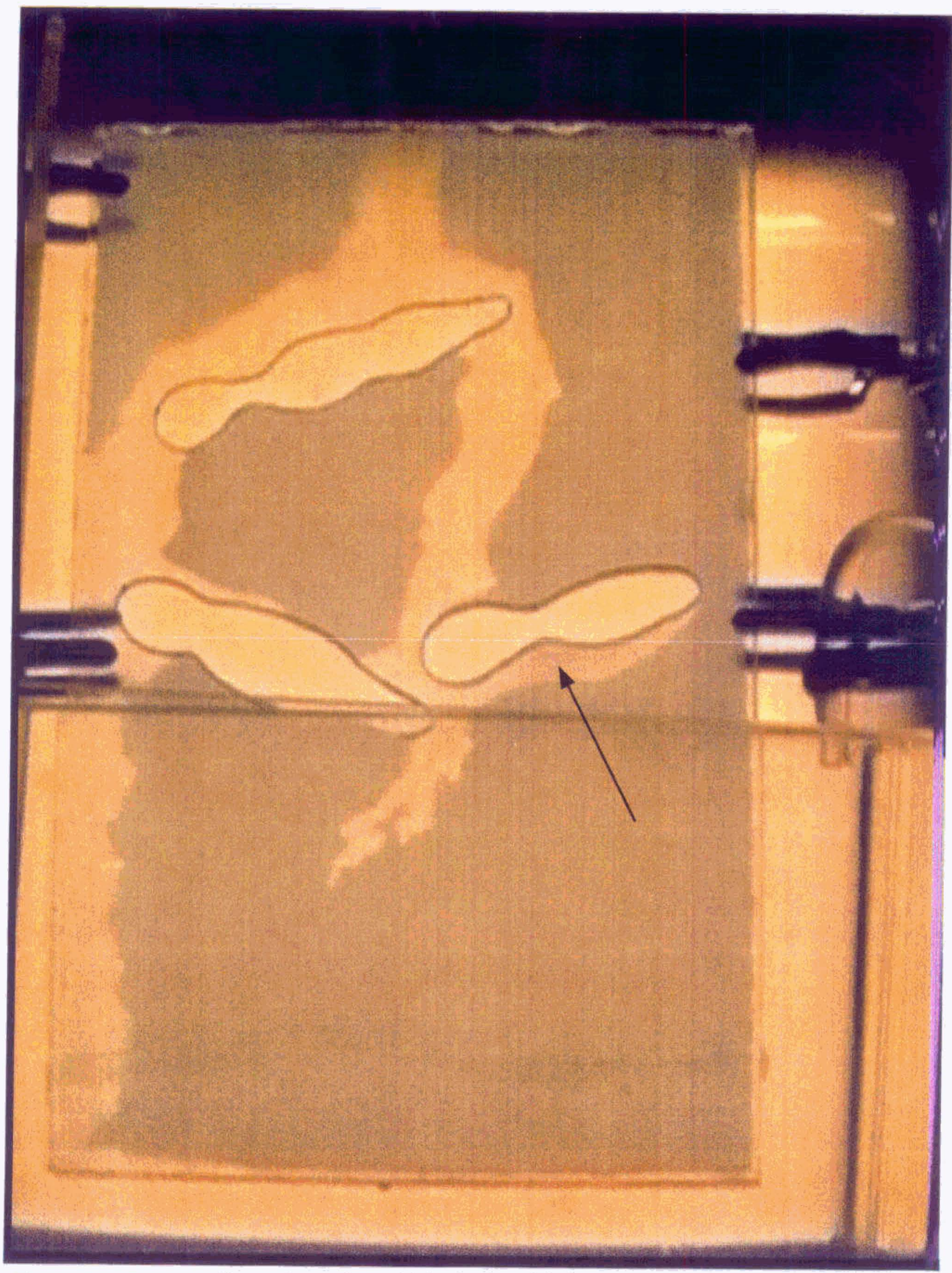

Figure 13. Seepage through model with impermeable barriers. Condensation halo identified with an arrow. Experiment 11, $\mathrm{T}_{\text {bath }}=35.3^{\circ} \mathrm{C}$ 


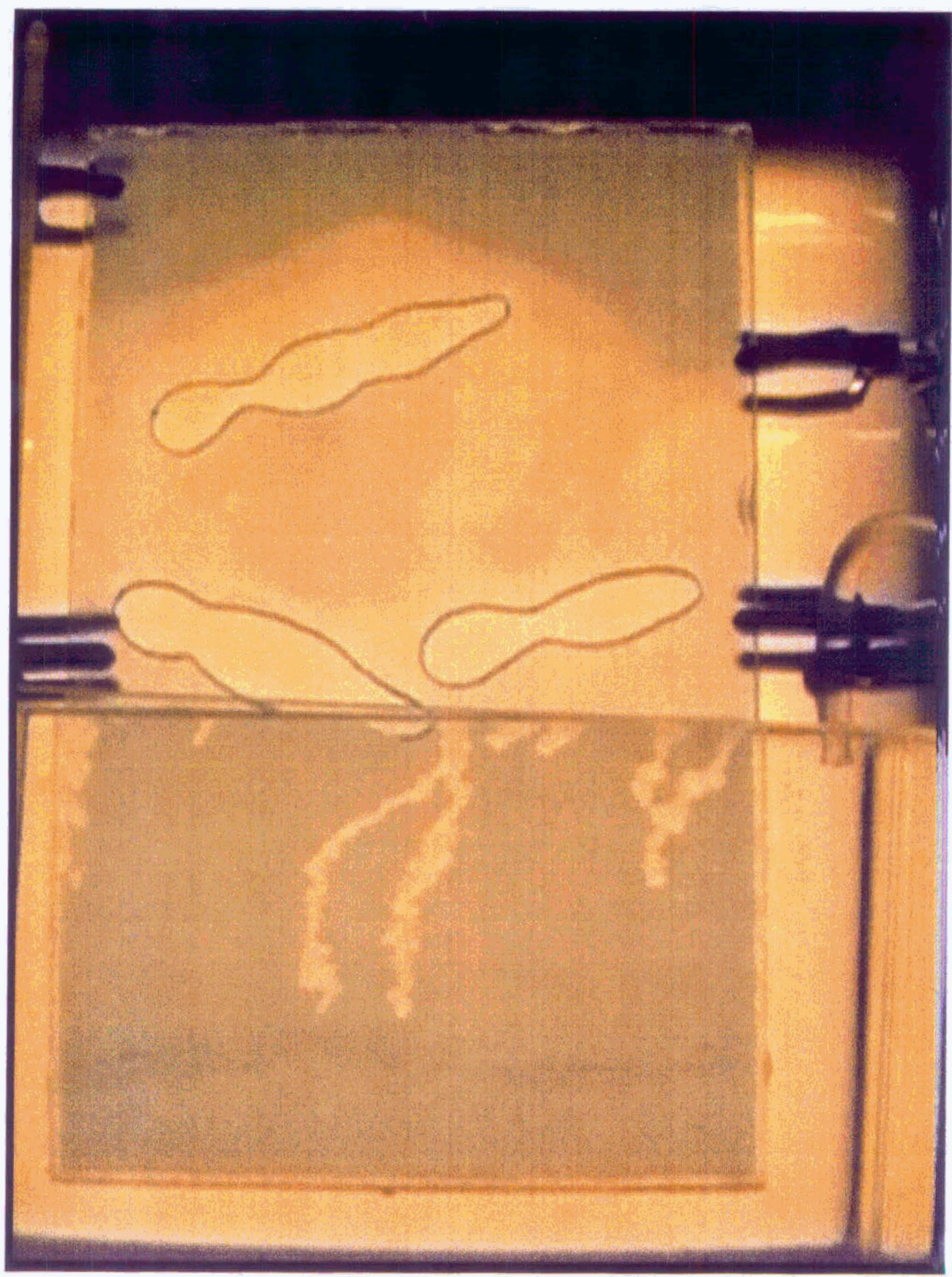

Figure 14. Longer fingers through model center. Experiment $11, \mathrm{~T}_{\mathrm{b}}$ ath $=37.1^{\circ} \mathrm{C}$ 


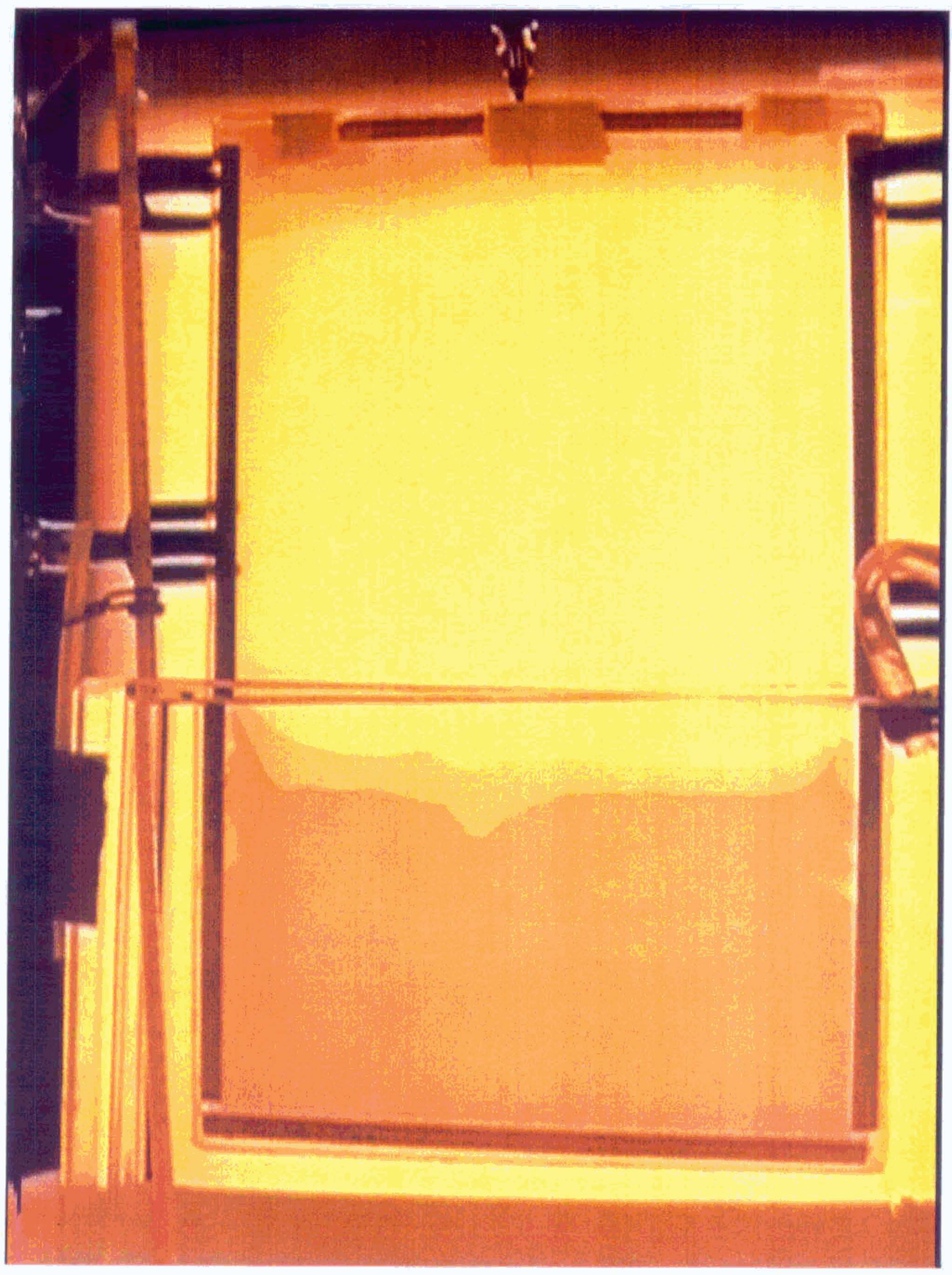

Figure 15. Pentane films. Experiment $12,38.6^{\circ} \mathrm{C}<\mathrm{T}_{\mathrm{b}}$ ath $<38.8^{\circ} \mathrm{C}$ 


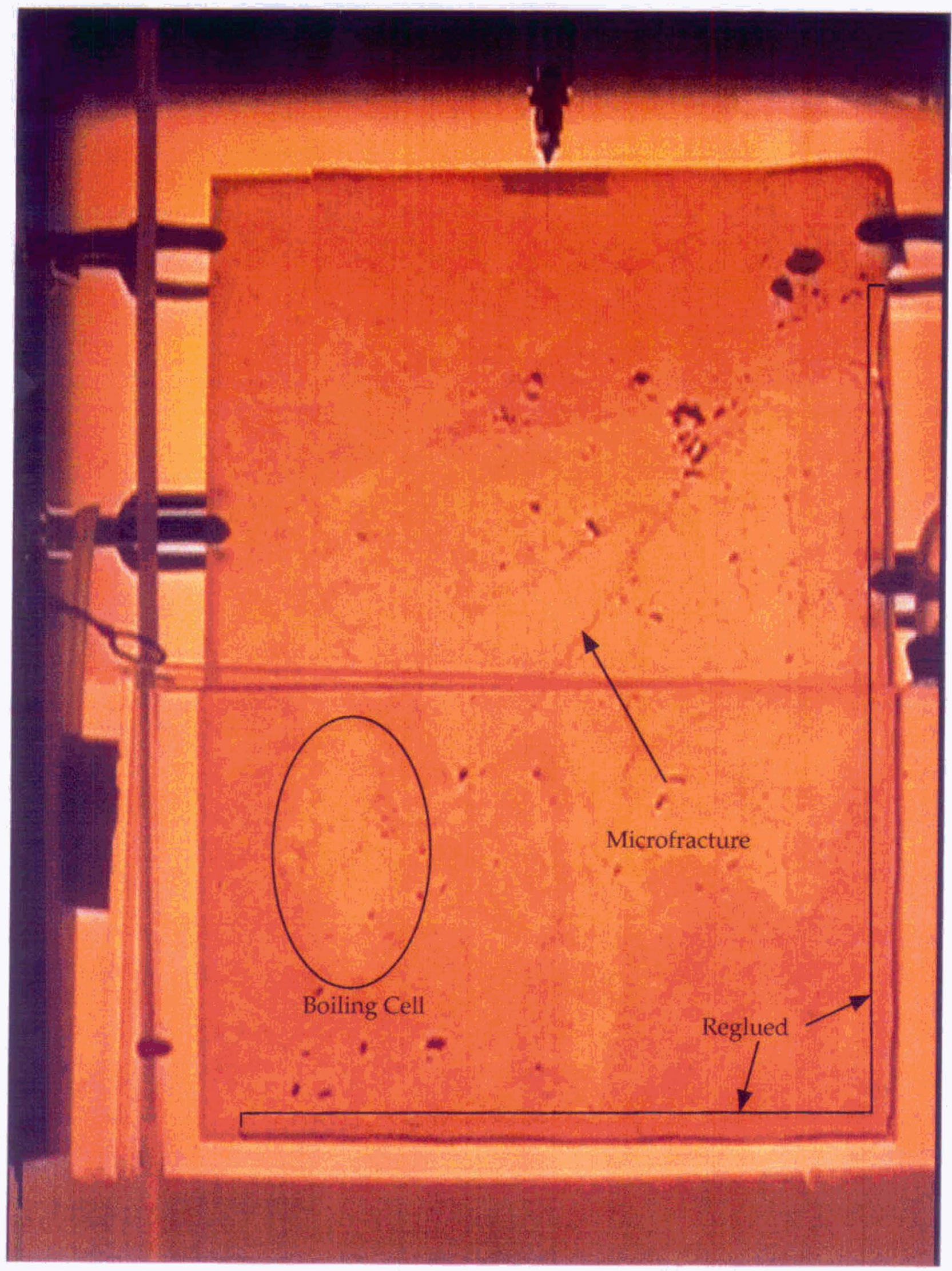

Figure 16. Films and fingers. Experiment $15, \mathrm{~T}_{\text {bath }}=39.0^{\circ} \mathrm{C}$ 


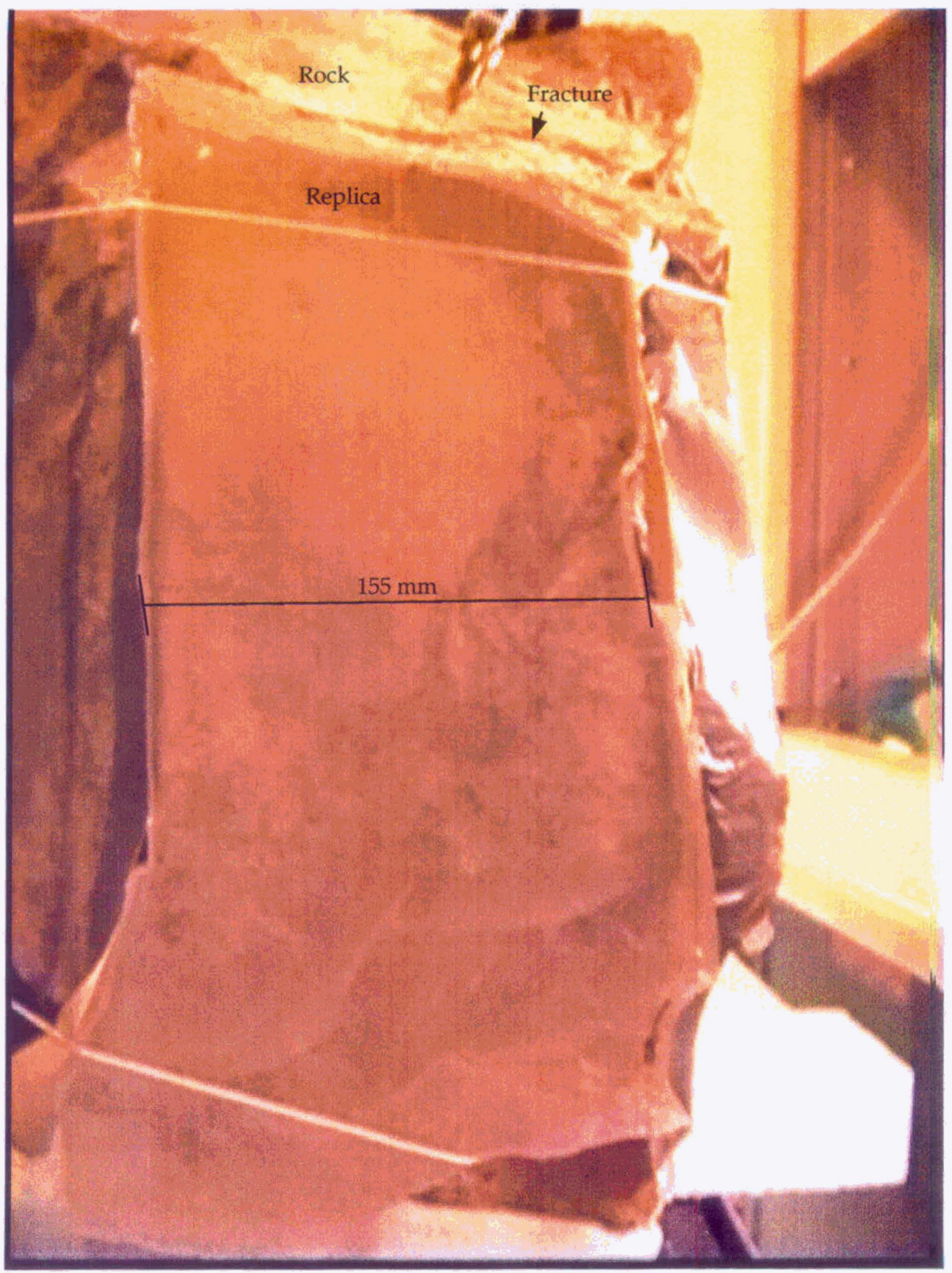

Figure 17. Rock-replica set-up. Experiment 16 


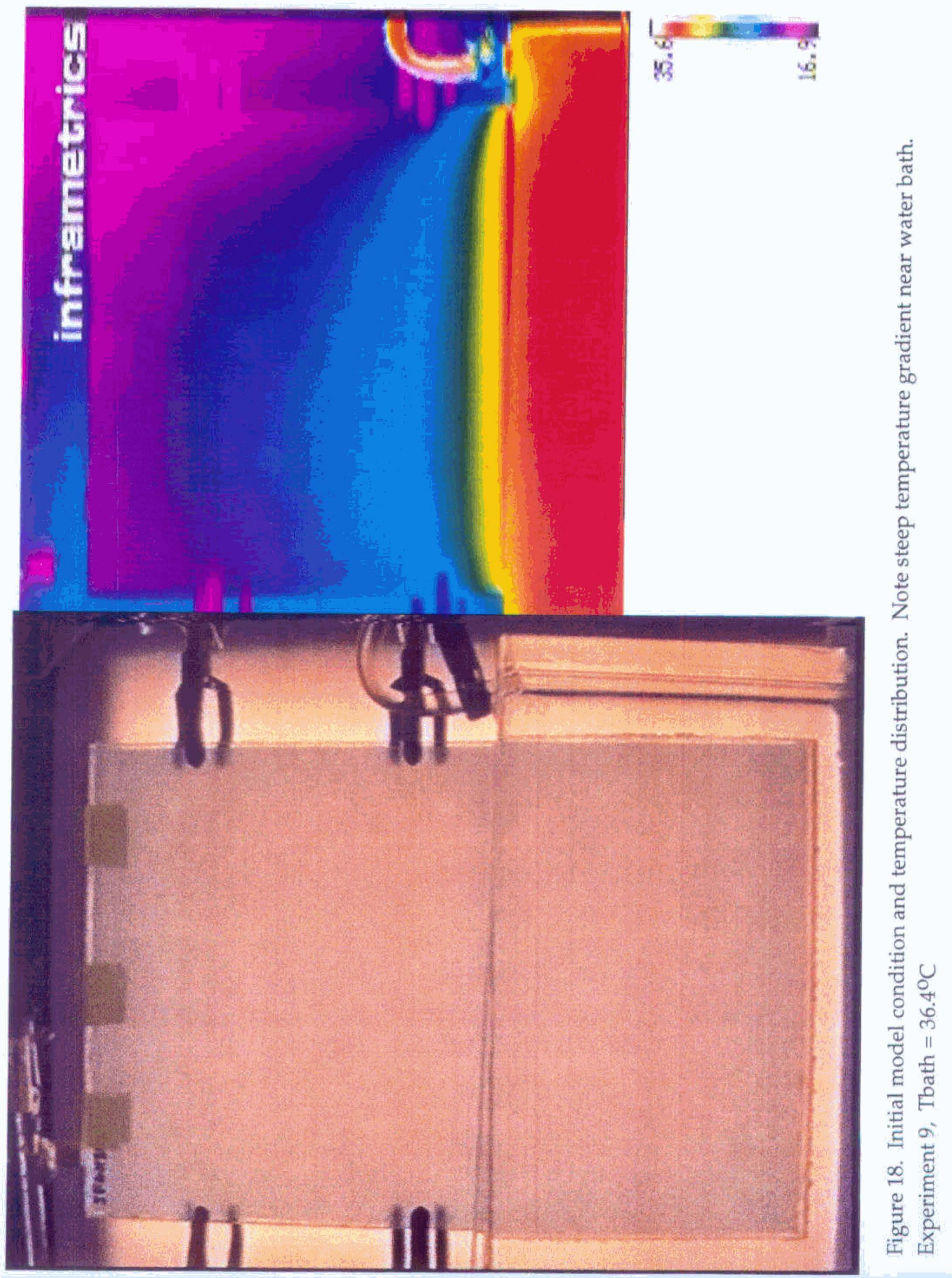



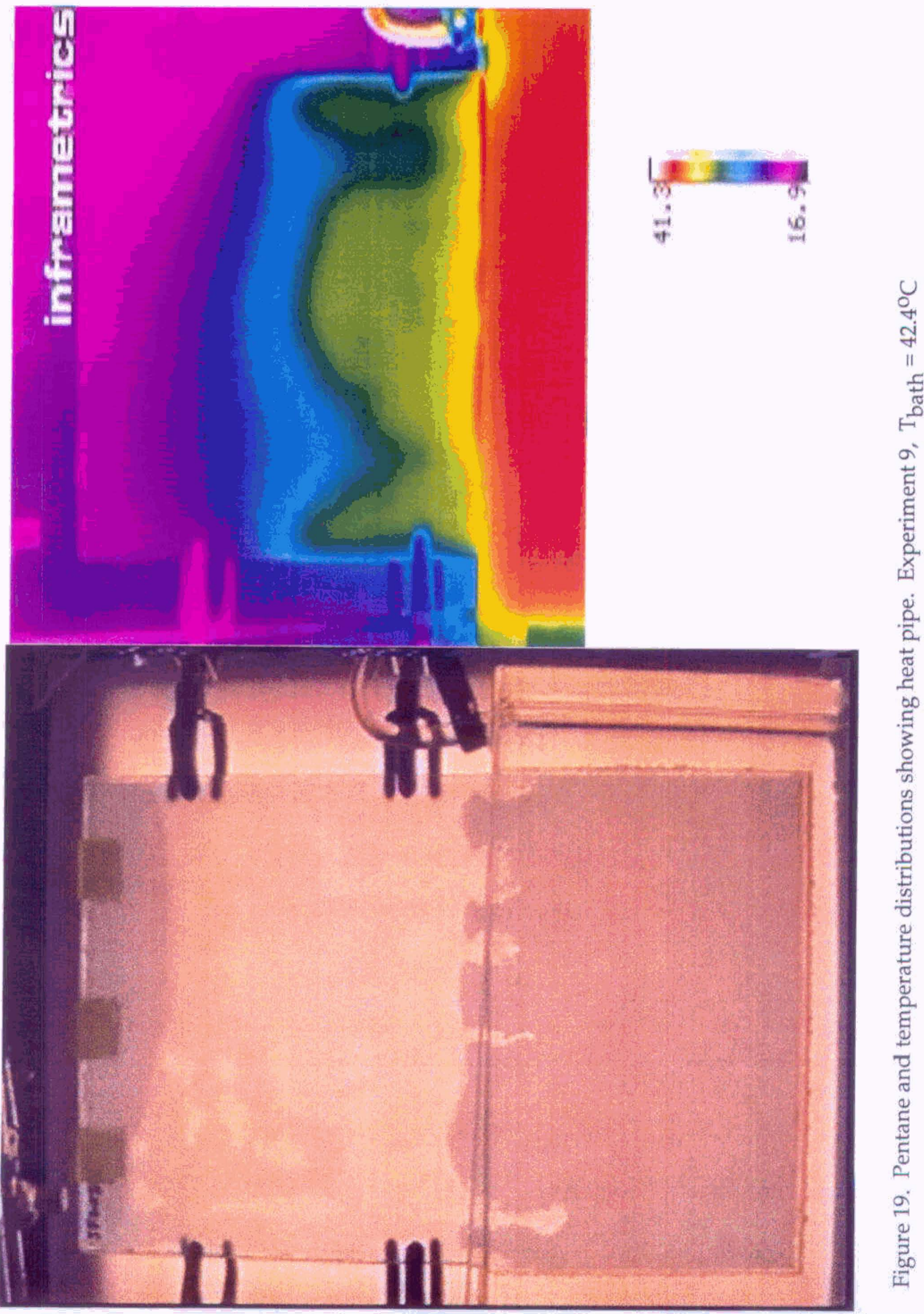


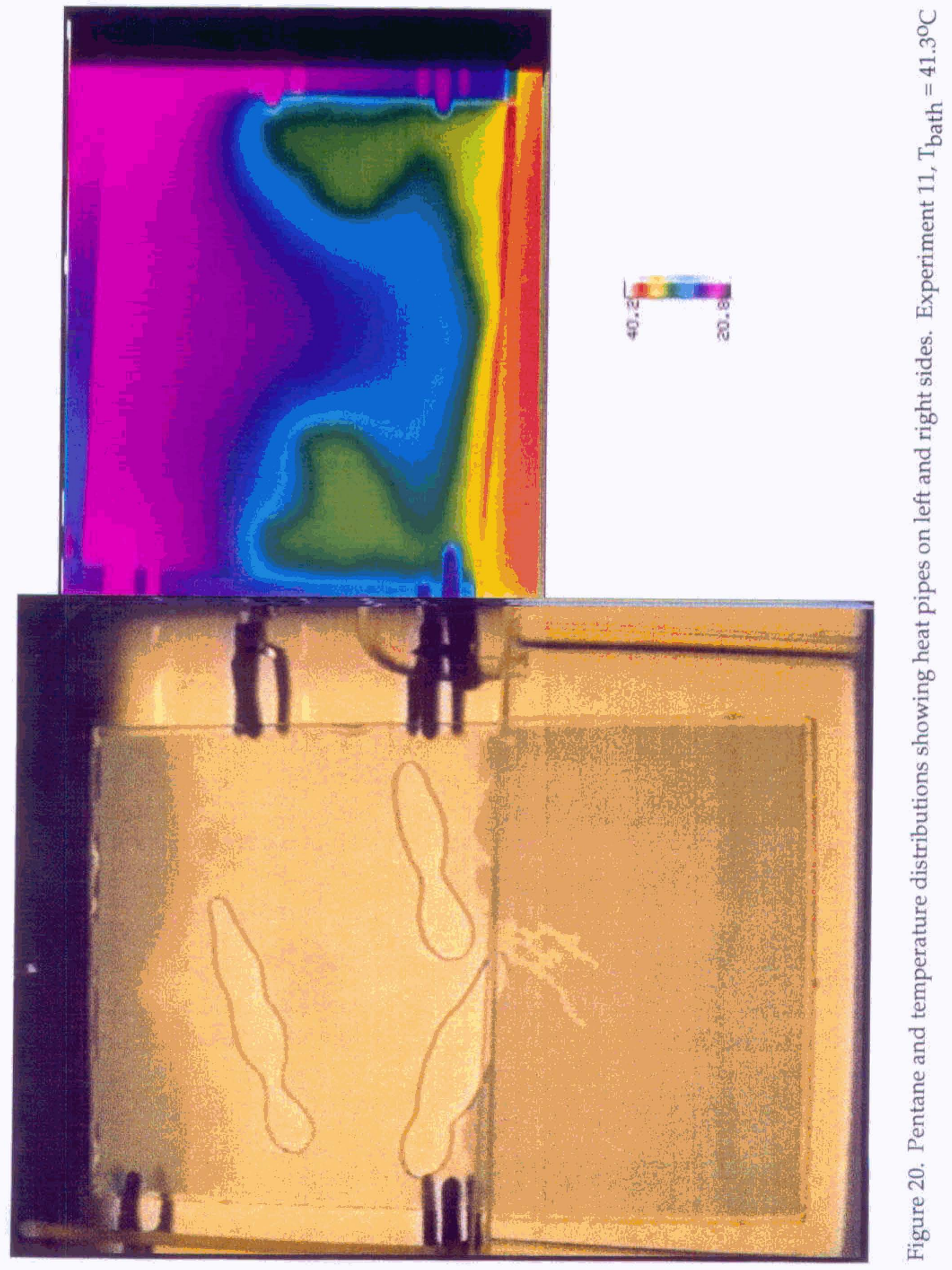




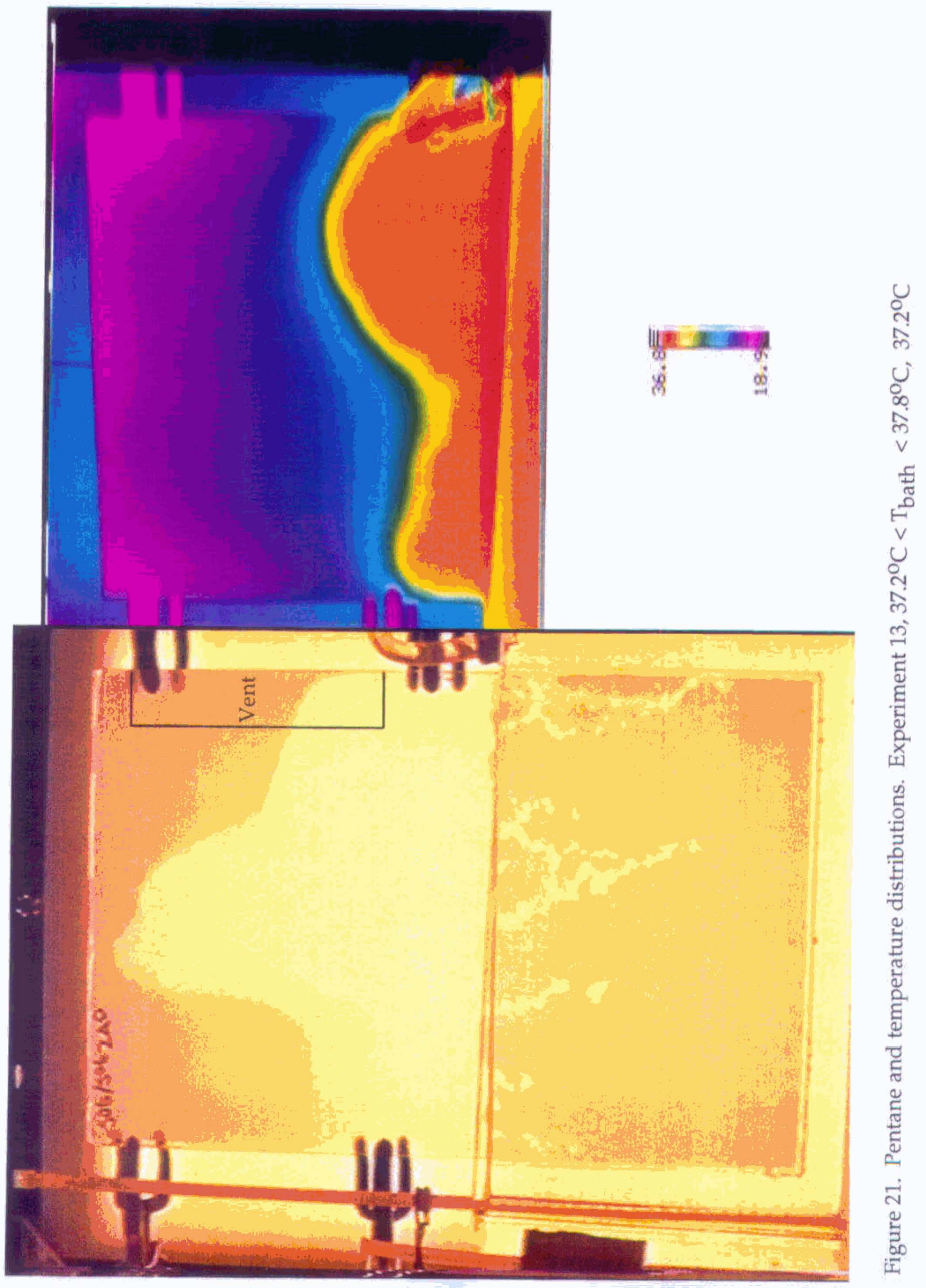




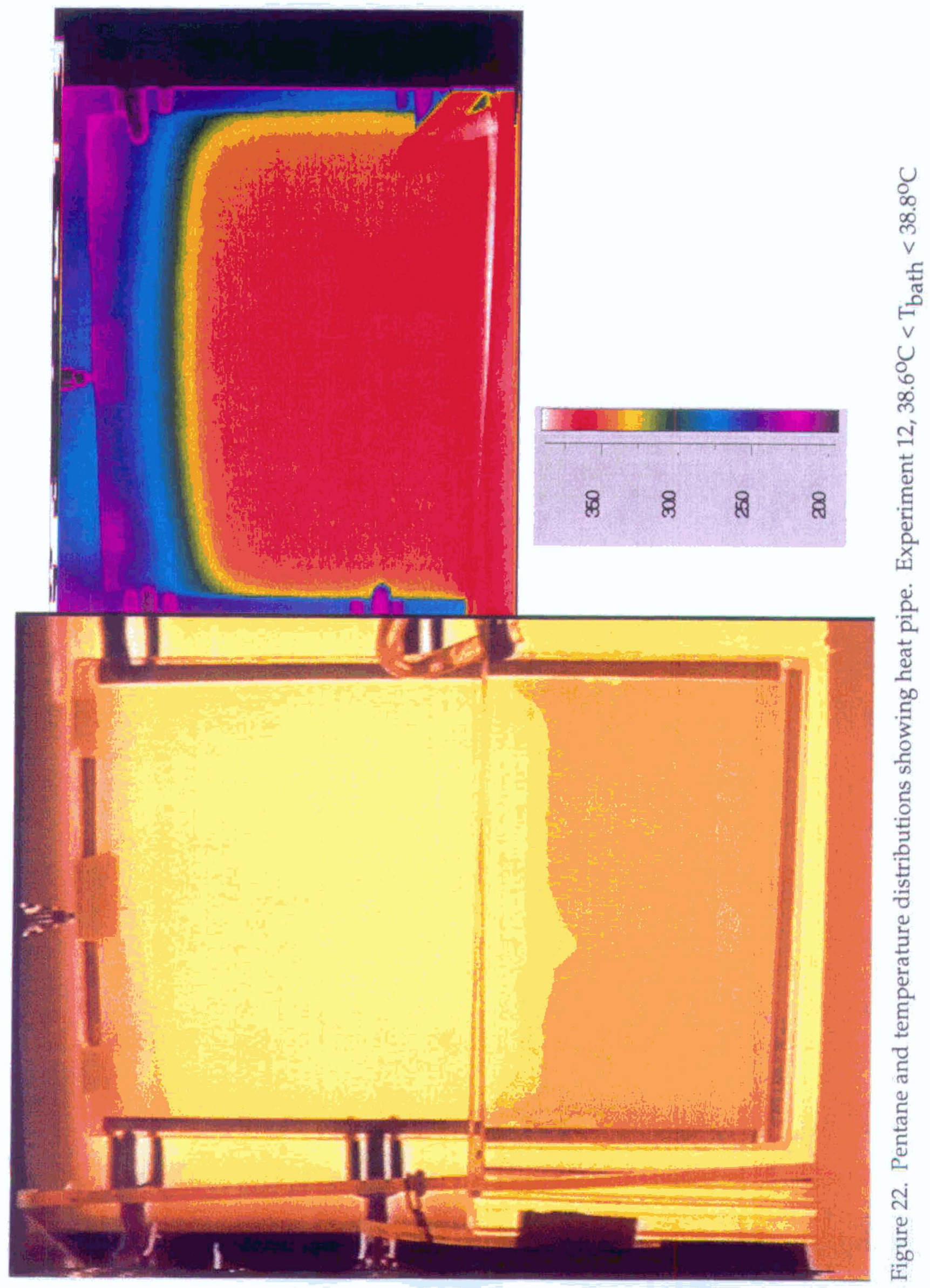




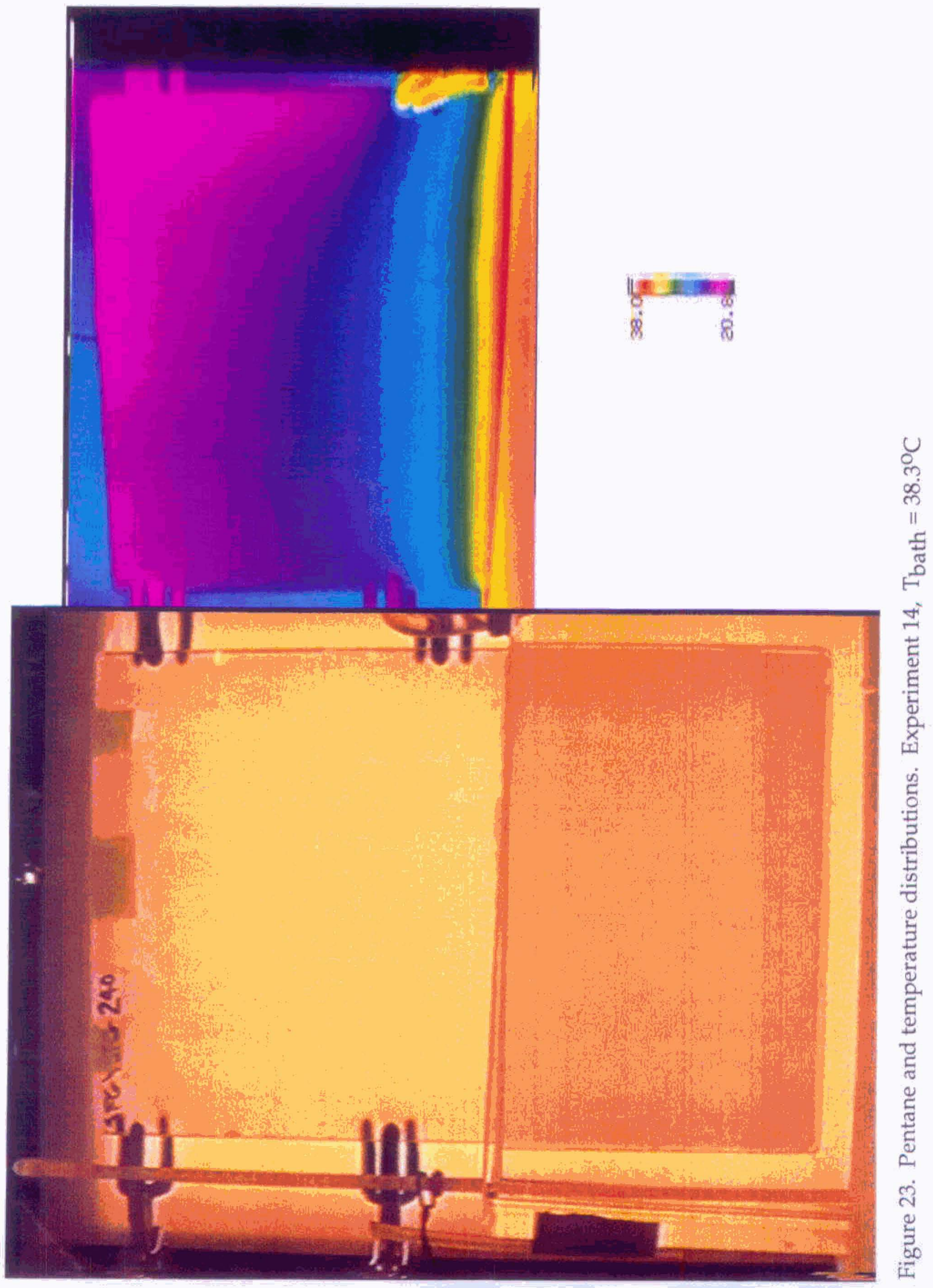




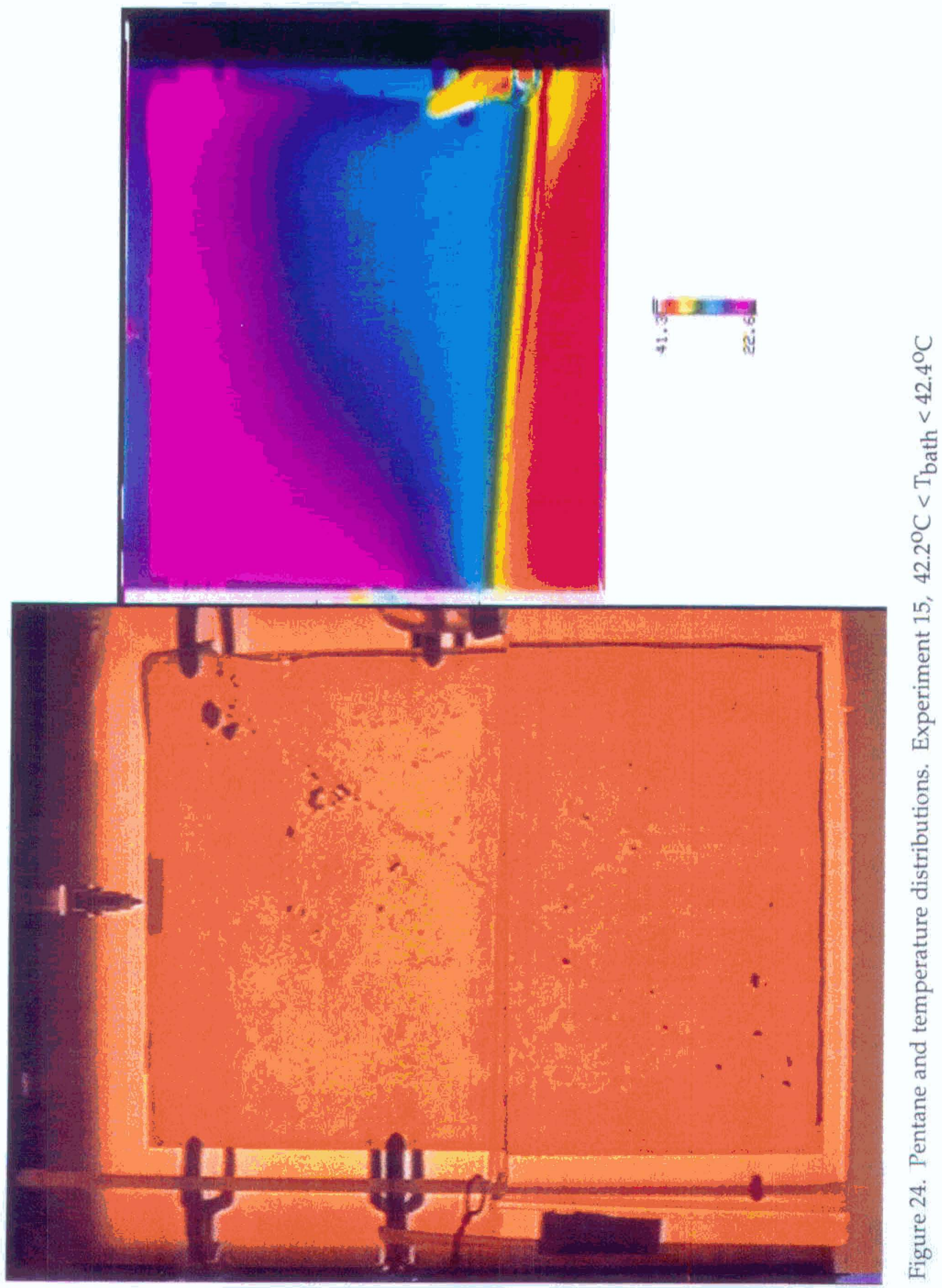




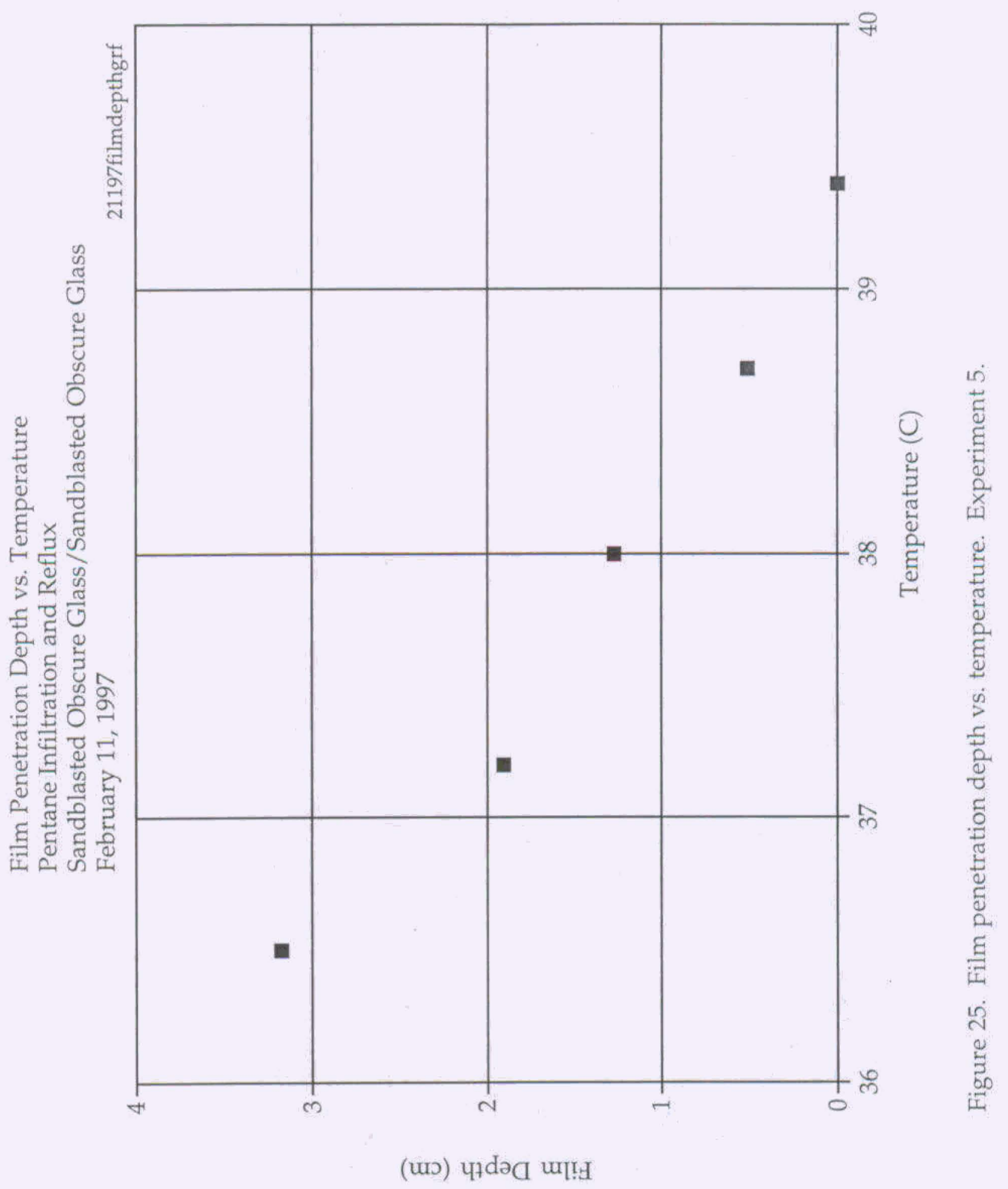




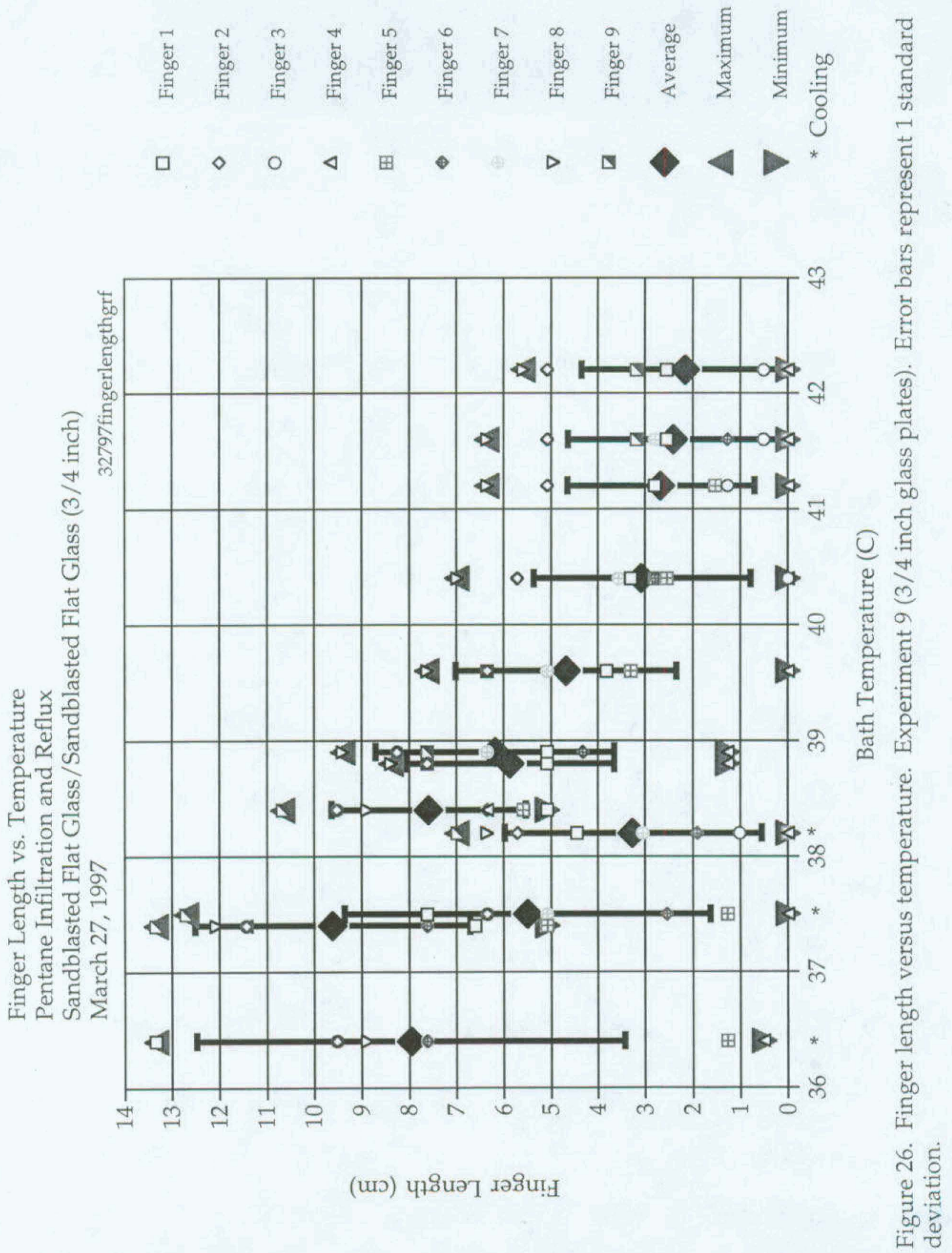




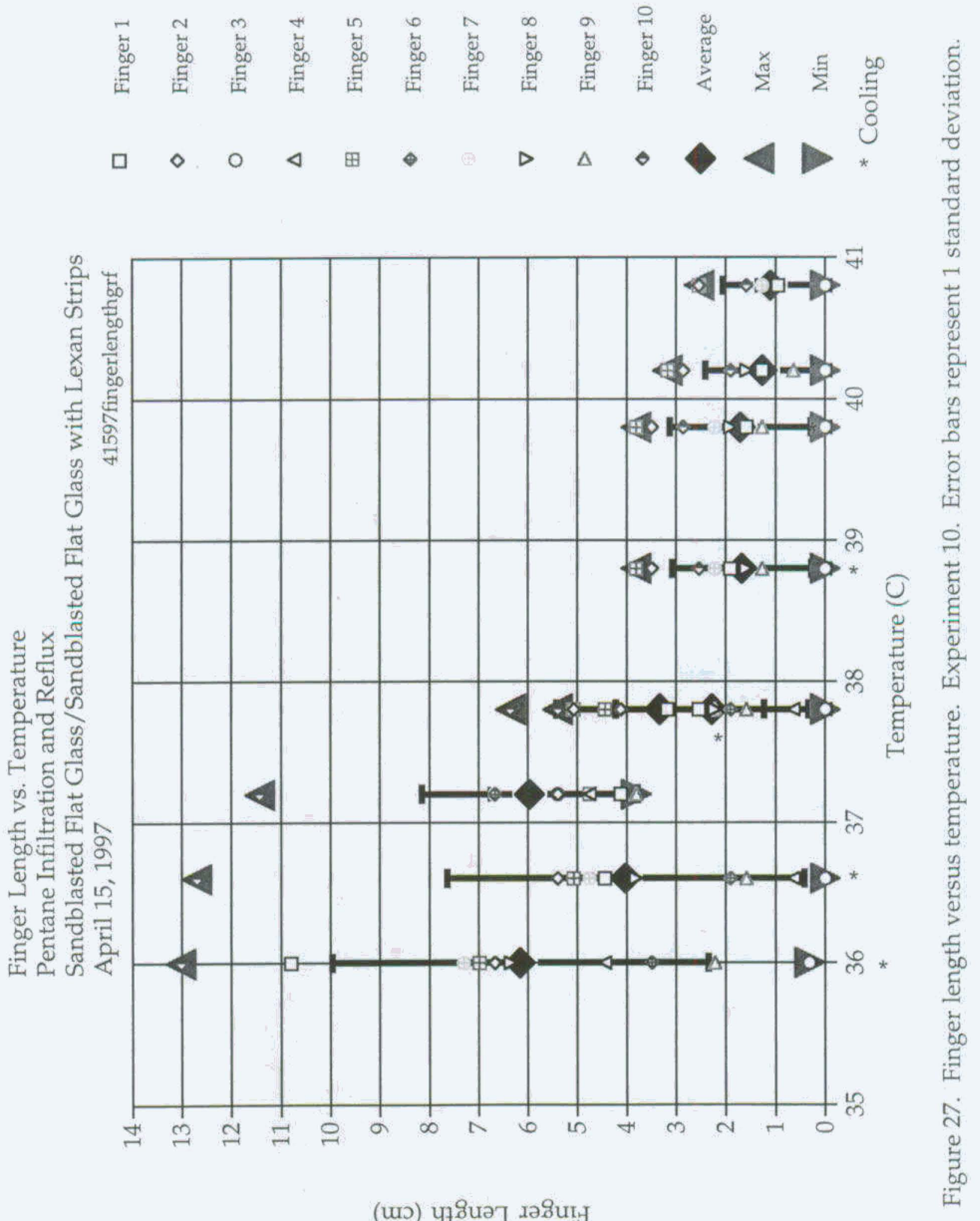

